Faculty of Science

Faculty Publications

This is a post-print version of the following article:

Hydroxymethylaniline Photocages for Carboxylic Acids and Alcohols

Dani Skalamera, Vesna Blazek Bregovic, Ivana Antol, Cornelia Bohne \& Nikola Basaric

November 2017

The final publication is available via American Chemical Society Publications at: https://doi.org/10.1021/acs.joc.7b02314

Citation for this paper:

Skalamera, D., Bregovic, V. B., Antol, I., Bohne, C., \& Basaric, N. (2017). Hydroxymethylaniline Photocages for Carboxylic Acids and Alcohols. Journal of Organic Chemistry, 82(23), 12554-12568. https://doi.org/10.1021/acs.joc.7b02314. 


\section{Hydroxymethylaniline photocages for carboxylic acids and alcohols}

Đani Škalamera, ${ }^{\dagger *}$ Vesna Blažek Bregović, ${ }^{\dagger}$ Ivana Antol, ${ }^{\dagger}$ Cornelia Bohne and Nikola Basarić $^{\dagger *}$

†Department of Organic Chemistry and Biochemistry, Ruđer Bošković Institute, Bijenička cesta 54, 10000 Zagreb, Croatia. Fax: + 38514680 195; Tel: +385 14561141

\$Department of Chemistry, University of Victoria, Box 1700 STN CSC, Victoria BC, V8W 2Y2, Canada.

Corresponding authors' E-mail addresses: DS dskalamera@chem.pmf.hr, NB nbasaric@irb.hr

\section{Graphical abstract}

The ortho cage can be recovered by chromatography and used again

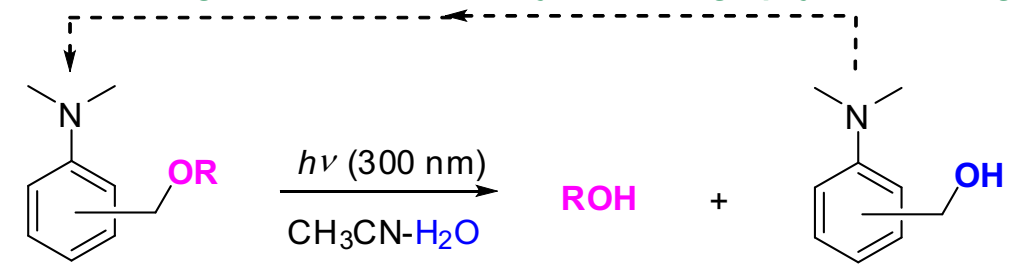

Comprehensive study of photoreaction mechanisms and utility as photocages for

$\mathrm{ROH}=$ carboxylic acid or alcohol $o, m$ and $p$-derivatives

Abstract: ortho-, meta- and para-Hydroxymethylaniline methyl ethers 3-5-OMe and acetyl derivatives 3-5-OAc were investigated as potential photocages for alcohols and carboxylic acids, respectively. The measurements of photohydrolysis efficiency showed that the decaging from ortho- and meta-derivatives takes place efficiently in aqueous solution, but not for the paraderivatives. Contrary to previous reports, we showthat the meta-derivatives are better photocages 
for alcohols, whereas ortho-derivatives are better protective groups for carboxylic acids. The observed differences were fully disclosed by mechanistic studies involving fluorescence measurements and laser flash photolysis (LFP). Photoheterolysis for the para-derivatives does not take place, whereas both meta- and ortho-derivatives undergo heterolysis and afford the corresponding carbocations 3-C and 4-C. The ortho-carbocation 4-o-C was detected byLFP in aqueous solution $\left(\lambda_{\max }=410 \mathrm{~nm}, \tau \approx 90 \mu \mathrm{s}\right)$. Moreover, spectroscopic measurements for the meta-acetyl derivative 3-m-OAC indicated the formation of cation in the excited state. The application of ortho- aniline derivative as protective group was demonstrated by synthesizing several derivatives of carboxylic acids. In all cases, the photochemical deprotection was accomplished in high yields ( $>80 \%)$. This mechanistic study fully rationalized photochemistry of aniline photocages which is important for design of new photocages and has potential for synthetic, biological and medicinal applications.

Key words: anilines, carbocation, laser flash photolysis, photocage, photochemistry, protective groups

\section{Introduction}

The use of protective groups is an inevitable strategy in multistep organic synthesis. With the increased number of synthetic steps, demands for the selective protection and deprotection of functional groups increases. Therefore, there are continuous efforts for the development of novel functional groups that can be selectively removed under specific conditions without the interference to other groups. This issue, called orthogonality of functional groups, has initiated numerous strategies for the selective removal of functional groups. ${ }^{1}$ Photoremovable protective 
groups, also called photocages, are particularly interesting in the context of reaction selectivity since only chromophores that are excited undergo reactions. Moreover, photochemical reactions do not require additional reagents, only photons of appropriate energy are required to initiate the reactions. In the last couple of decades several classes of photocages have been developed and their chemistry has been reviewed on several occasions. ${ }^{2,3,4,5,6,7,7}$

One of the most commonly used classes of photocages are $o$-nitrobenzyl alcohol derivatives $1 .^{2-8}$ Therefore, photochemistry of $o$-nitrobenzyl ethers has been investigated in detail. ${ }^{9,10}$ Owing to the fact that this group can be excited by visible light, it has been applied in biology and medicine, initially for the decaging of $\mathrm{ATP},{ }^{11}$ and later for other applications including the release of folic acid, ${ }^{12}$ decaging of neurotransmitters, ${ }^{13}$ modification of proteins, ${ }^{14}$ or in molecular imaging. ${ }^{15}$ However, the use of $o$-nitrobenzyl protective groups have some drawbacks that include reactive nitroso-aromatic side-products and their internal optical effects. Furthermore, serious drawback of the $o$-nitrobenzyl alcohol derivatives is the fact that the cleavage of the protective group does not take place in the photochemical step, but in a rather slow $\left(k=0.1-5 \mathrm{~s}^{-1}\right)^{10}$ thermal step that follows the photochemical reactions. Thus, the $o$ nitrobenzyl group is not the best candidate when spatial and temporal control of the photocleavage is required. Much better options are groups where photodeprotection takes place in a photochemical reaction which is intrinsically fast. For example, a significant endeavor has been devoted to the development of $p$-hydroxyphenacyl photocages whose deprotection is based on photo-Favorsky reaction, ${ }^{16,17,18,19,20,21}$ or carbanion-mediated decaging from benzophenone ${ }^{22}$ or xanthone derivatives. ${ }^{23}$ 
$\mathrm{O}^{-\mathrm{R}}$

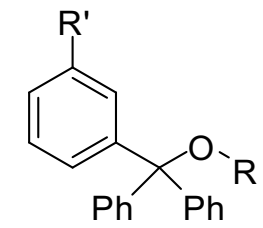

$\mathrm{R}^{\prime}=$ O-alkyl

$=\mathrm{N}, \mathrm{N}$-dimethylamine

2

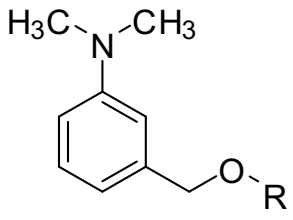

3

Wang et al. reported on the use of trityl derivatives 2 as photocages for alcohols ${ }^{24,25}$ Although it was not explicitly inferred, these groups likely undergo photo-decaging in the photochemical reaction via carbocation intermediates and not in the slow post-photochemical thermal processes. However, one of the serious problems of the trityl derivatives is their thermal instability, particularly in acidic conditions. Furthermore, Wang et al. have recently reported an example of photocage for alcohols based on the cleavage of meta-hydroxymethylaniline ethers $3{ }^{26,27}$ The photocage $\mathbf{3}$ is superior to the previously described trityl derivatives $\mathbf{2}$, since $\mathbf{3}$ does not undergo photorelease of the substrates unless irradiated, overcoming the thermal instability problem. Based on the isolated products, the decaging reaction probably proceeds via a heterolytic cleavage and carbocation that was not spectroscopically characterized. Wang et al. extended the scope of their photocage to amine derivatives, where by deuterium labeling they indirectly supported the formation of carbocation intermediates. ${ }^{28}$ Aniline photocages were also extended in a larger phenylquinoline chromophoric system where their applicability to decage carboxylic acid under two photon excitation has been demonstrated. ${ }^{29}$ Recently, Wang et al. demonstrated that ortho-aniline derivatives can also be used as photocages for alcohols and carboxylic acids. ${ }^{30}$ These studies show the potential of the use of anilines as photocages and mechanistic studies, which until now have been sparse, are required to understand the breadth and limitation for the use of these photocages. To achieve this mechanistic understanding we present a more general 
investigation of the applicability of hydroxymethylaniline derivatives as photocages for alcohols and carboxylic acids and demonstrated differences between them. We have prepared a series of 9 aniline derivatives bearing ortho-, meta- or para-hydroxymethyl group 3-5-OH, which were transformed to the corresponding ethers 3-5-OMe or esters 3-5-OAc. The efficiency of photodecaging was investigated, and our main finding is that the meta-derivatives are better photocages for alcohols, whereas the ortho-derivatives are better protective groups for carboxylic acids, contrary to previous reports. ${ }^{30}$ The mechanism of the decaging reaction was studied by fluorescence spectroscopy and laser flash photolysis (LFP) where we have detected carbocation intermediates. Moreover, using the versatile ortho-aniline photocage derived from chloride $o-7$ we have demonstrated the applicability to photochemically release amino acids, neurotransmiter GABA, and nonsteroidal anti-inflammatory drug ibuprofen, indicating its applicability as photocage in organic synthesis, biology and medicine.

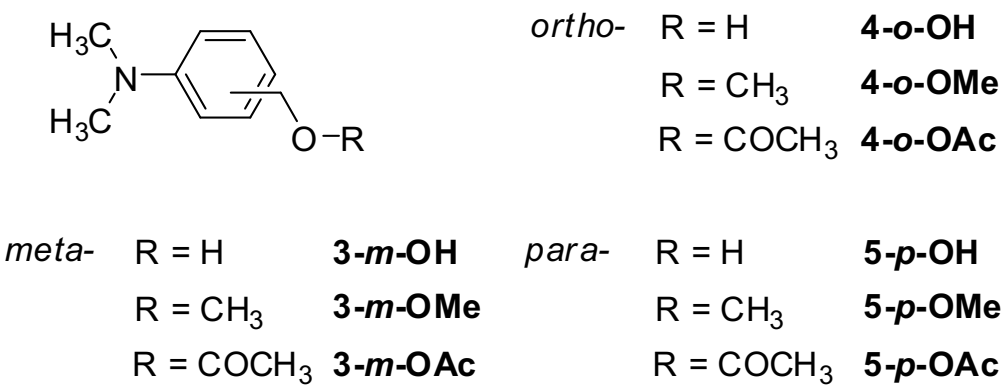

\section{Results}

\section{Synthesis}

Aniline derivatives 3-5 were synthesized in good to excellent yields from the corresponding hydroxyanilines ortho-, meta- or para-6, that were methylated in a reductive formylation ${ }^{31}$ (for 
the meta- and para-derivatives) or by methyl iodide (for the ortho-derivative) in the presence of sodium dihydrogenphosphate, as described by Wang et al. (Scheme 1). ${ }^{26}$ Alcohols 3-5-OH were acetylated by acetyl chloride to the corresponding esters 3-5-OAc. For the preparation of methyl ethers, ortho- and meta- alcohols were transformed to the corresponding chlorides 7 in the presence of thionyl chloride and subsequently in the reaction with sodium methoxyde transformed to ethers 3-m-OMe and 4-p-OMe. The para- alcohol was converted to the corresponding methyl ether in methanol under acidic conditions (Scheme 2).

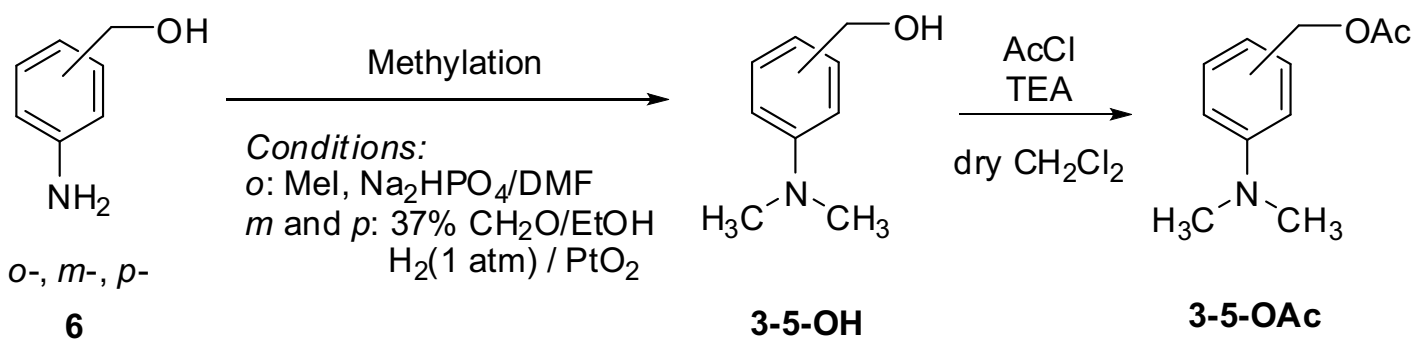

Scheme 1.

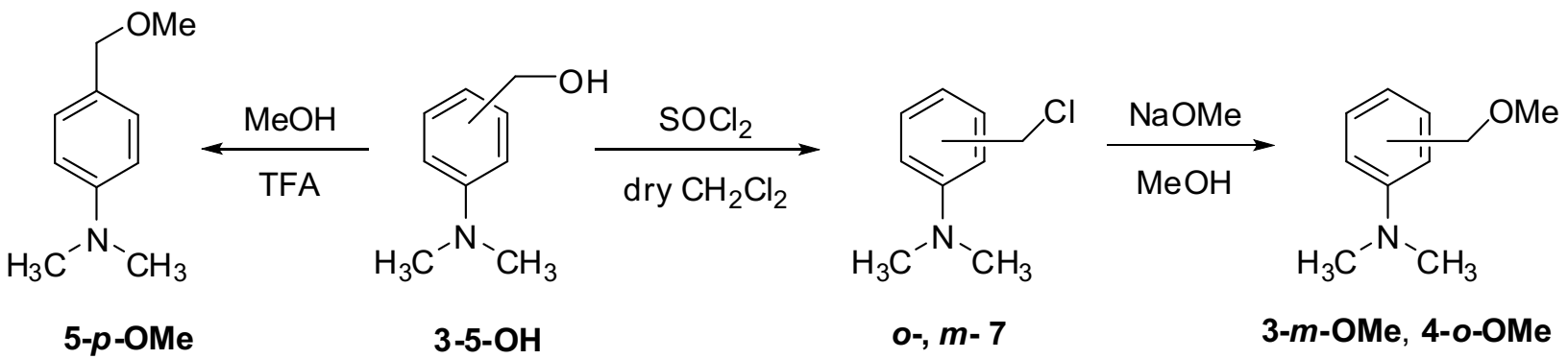

Scheme 2.

\section{Photochemistry}

Applicability of anilines 3-5-OMe and 3-5-OAc as photocages was investigated by preparative irradiations $(300 \mathrm{~nm})$ in $\mathrm{CH}_{3} \mathrm{CN}-\mathrm{H}_{2} \mathrm{O}$ whereupon the compounds underwent photohydrolysis giving the corresponding alcohols 3-5-OH. Irradiation of ortho-derivatives 4 gave in addition to 
the anticipated alcohol 4-o-OH (70\%), carbaldehyde 8 and methyl derivative $\mathbf{9}$, formed in small quantities. To fully characterize the minor photoproducts $\mathbf{8}$ and $\mathbf{9}$, they were prepared in a larger amount by an independent synthetic method. Carbaldehyde 8 was obtained by oxidation of 4-o$\mathbf{O H}$ in a Dess-Martin reaction, whereas methyl derivative 9 was prepared by reductive formylation of $o$-toludine (Scheme 3).
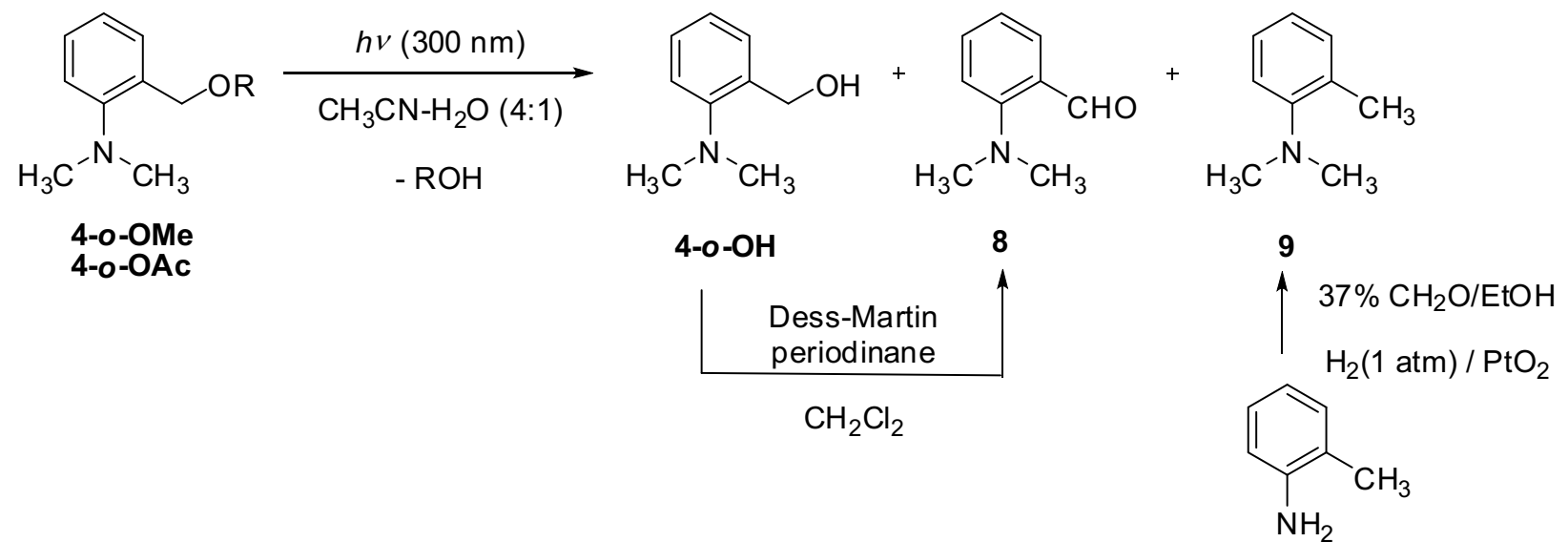

Scheme 3.

Irradiation (300 nm) of meta-derivatives 3-m-OMe and 3-m-OAc gave the anticipated alcohol 3$\boldsymbol{m}-\mathbf{O H}$ as a major product $(80 \%)$, and $N$-acetyl derivative $\mathbf{1 0}(9 \%$, Scheme 4$)$ formed by an attack of acetonitrile to the photochemically generated carbocation (vide infra) and subsequent hydrolysis. Both products were isolated from the photolysis mixture. Moreover, a larger amount of $N$-acetyl derivative $\mathbf{1 0}$ was prepared by an independent synthetic method where chloride $m$-7 was transformed to the amine with ammonia and acetylated with acetyl chloride. 


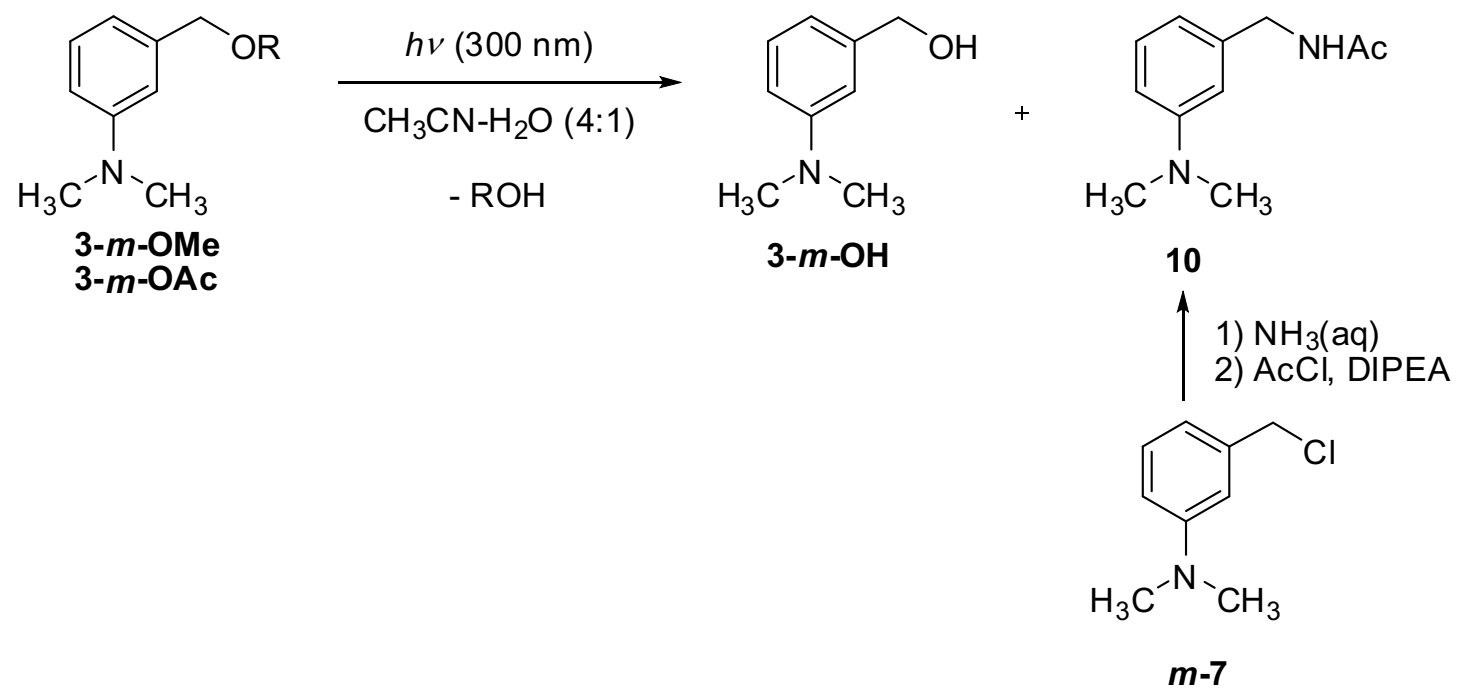

Scheme 4.

Photochemical deprotection of alcohol and acid was also demonstrated by irradiation (300 nm) of the para-derivatives 5-p-OMe and 5-p-OAc (Scheme 5). The photohydrolysis reaction was clean, giving mainly alcohol 5-p-OH, but it was very inefficient. To achieve a satisfactory conversion to 5-p-OH ( $>90 \%$ ), a long irradiation was required (3h).

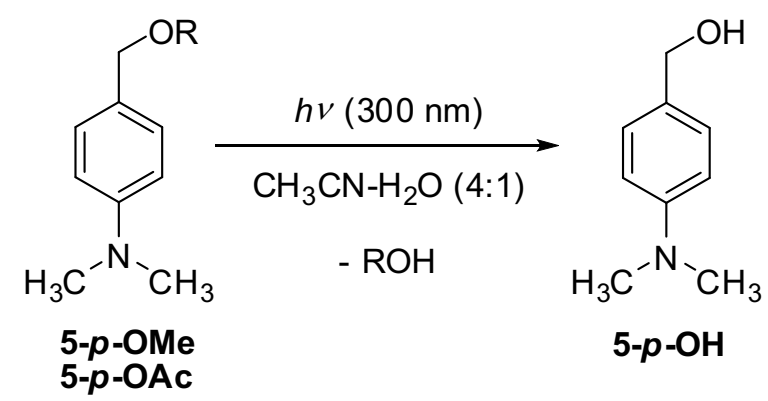

Scheme 5.

Long irradiations ( $5 \mathrm{mg}, 3 \mathrm{~h}, 300 \mathrm{~nm}$ ) of 5-p-OMe gave in addition to 5-p-OH compound $\mathbf{1 1}$ $(\approx 5 \%)$ that was detected by HPLC compared to the commercial chemical. Formation of methyl derivative 11 suggested the presence of radical intermediates, which was also probed by the irradiation of 5-p-OMe in the presence of ethanethiol, an ubiquitous radical trapping reagent. It gave thioether 12 which was detected by HPLC, formed in $8 \%$ yield, which was proven by 
comparison with the sample obtained in an independent synthesis from 5-p-OH by the treatment with ethanethiol in the presence of TFA.<smiles>Cc1ccc(N(C)C)cc1</smiles>

11<smiles>CCCc1ccc(N(C)C)cc1</smiles>

12

Applicability of the aniline ethers and acetyl derivatives as photocages was investigated further by measuring quantum efficiencies of the photohydrolysis reactions. The efficiency was determined for the $\mathrm{CH}_{3} \mathrm{CN}$ or $\mathrm{CH}_{3} \mathrm{CN}-\mathrm{H}_{2} \mathrm{O}$ (4:1) solution at $\mathrm{pH} 7$ in the presence of phosphate buffer $(c=0.01 \mathrm{M})$ by use of $\mathrm{KI} / \mathrm{KIO}_{3}$ actinometer $\left(\Phi_{254}=0.74\right) .{ }^{32,33}$ The measured efficiency for the compound decomposition $\left(\Phi_{\mathrm{R}}\right)$ and photohydrolysis $\left(\Phi_{\mathrm{OH}}\right)$ are compiled in Table 1 . An important aspect in the use of anilines as photocages is the selectivity of photohydrolysis, which is best demonstrated from the difference in values of $\Phi_{\mathrm{R}}$ and $\Phi_{\mathrm{OH}}$. The reaction is more selective if $\Phi_{\mathrm{R}}$ and $\Phi_{\mathrm{OH}}$ are close.

Table 1. Quantum yields for the photohydrolysis of aniline derivatives 3-5 and uncaging cross section $\left(\Phi_{\mathrm{R}} \varepsilon_{254}\right){ }^{\mathrm{a}}$

\begin{tabular}{|l|l|l|l|}
\hline Compound / solvent & $\Phi_{\mathrm{R}}^{\mathrm{b}}$ & $\Phi_{\mathrm{R}} \varepsilon_{254} / \mathrm{M}^{-1} \mathrm{~cm}^{-1}$ & $\Phi_{\mathrm{OH}^{c}}$ \\
\hline 4-o-OMe $/ \mathrm{CH}_{3} \mathrm{CN}$ & $0.047 \pm 0.006$ & $270 \pm 30$ & \\
\hline 4-o-OMe $/ \mathrm{CH}_{3} \mathrm{CN}-\mathrm{H}_{2} \mathrm{O}^{\mathrm{d}}$ & $0.17 \pm 0.02$ & $1000 \pm 100$ & $0.111 \pm 0.005$ \\
\hline 4-o-OAc $/ \mathrm{CH}_{3} \mathrm{CN}$ & $0.019 \pm 0.004$ & $110 \pm 20$ & \\
\hline 4-o-OAc $/ \mathrm{CH}_{3} \mathrm{CN}-\mathrm{H}_{2} \mathrm{O}^{d}$ & $0.26 \pm 0.04$ & $1500 \pm 200$ & $0.20 \pm 0.01$ \\
\hline 3-m-OMe $/ \mathrm{CH}_{3} \mathrm{CN}$ & $0.033 \pm 0.003$ & $360 \pm 30$ & \\
\hline
\end{tabular}




\begin{tabular}{|l|l|l|l|}
\hline 3-m-OMe $/ \mathrm{CH}_{3} \mathrm{CN}-\mathrm{H}_{2} \mathrm{O}$ & $0.45 \pm 0.05$ & $5000 \pm 500$ & $0.38 \pm 0.02$ \\
\hline 3-m-OAc $/ \mathrm{CH}_{3} \mathrm{CN}$ & $0.022 \pm 0.006$ & $280 \pm 80$ & \\
\hline 3-m-OAc $/ \mathrm{CH}_{3} \mathrm{CN}-\mathrm{H}_{2} \mathrm{O}^{\mathrm{d}}$ & $0.08 \pm 0.02$ & $1000 \pm 200$ & $0.034 \pm 0.004$ \\
\hline 5-p-OMe $/ \mathrm{CH}_{3} \mathrm{CN}-\mathrm{H}_{2} \mathrm{O}$ & $0.005 \pm 0.002$ & $40 \pm 16$ & $0.005 \pm 0.002$ \\
\hline 5-p-OAc $/ \mathrm{CH}_{3} \mathrm{CN}-\mathrm{H}_{2} \mathrm{O}$ & $0.007 \pm 0.002$ & $80 \pm 20$ & $0.007 \pm 0.002$ \\
\hline
\end{tabular}

${ }^{a}$ Measurements were conducted by irradiating at $254 \mathrm{nmin} \mathrm{CH}_{3} \mathrm{CN}$ or $\mathrm{CH}_{3} \mathrm{CN}-\mathrm{H}_{2} \mathrm{O}$ (4:1) by use of $\mathrm{KI} / \mathrm{KIO}_{3}$ actinometer $\left(\Phi_{254}=0.74\right) .{ }^{32,33}$ Measurements were done in triplicate and the mean value is reported. The quoted error corresponds to the maximum absolute deviations.

${ }^{\mathrm{b}}$ Quantum yield of compound decomposition, $\Phi_{\mathrm{R}}$ was calculated according to Eq. S1-S5 in the supporting information.

${ }^{\mathrm{c}}$ Quantum yield for the formation of hydrolysis product $\Phi_{\mathrm{OH}}$ was calculated according to Eq. S1$\mathrm{S} 5$ in the supporting information.

${ }^{d}$ The measurements conducted in $\mathrm{CH}_{3} \mathrm{CN}-\mathrm{H}_{2} \mathrm{O}(1: 4)$ in the absence or presence of phosphate buffer $(c=0.01 \mathrm{M}, \mathrm{pH}=7.0)$ gave the same values for $\Phi_{\mathrm{R}}$ and $\Phi_{\mathrm{OH}}$.

Generally, the efficiency for the aniline decomposition $\left(\Phi_{R}\right)$ in aqueous solution is significantly higher than in $\mathrm{CH}_{3} \mathrm{CN}$ (Table 1), which is in line with the increased polarity of the aqueous solvent needed for the stabilization of the photochemically formed carbocation, as well as the availability of nucleophiles for the reaction with the carbocation. Moreover, ortho- and meta- are more reactive then the para-derivatives, which is in accord with the well-known meta-effect in photochemistry. ${ }^{34,35}$ Although photolysis of para-anilines 5-p-OMe and 5-p-OAc proceeds cleanly to $\mathbf{5 - p - O H}$, the reaction is inefficient which precludes any synthetic or biological applicability. 
Meta-derivatives showed unexpected reaction efficiency. Although acetyl is a better leaving group than the methoxy group, photodecomposition of 3-m-OAcin aqueous solution takes place about five times less efficiently than observed for3-m-OMe. Moreover, the decomposition efficiency $\Phi_{\mathrm{R}}$ for 3-m-OAc is about two times higher than the photohydrolysis efficiency $\left(\Phi_{\mathrm{OH}}\right.$, Table 1). Therefore, meta-aniline is not a good photocage for carboxylic acids, but it is good for the photorelease of alcohols, as it has been demonstrated by Wang et al. ${ }^{30}\left(\Phi_{\mathrm{R}}=0.26\right.$ for the cleavage of ether and decaging of rhamnoside) ${ }^{26}$ On the other hand, ortho-anilines are better photocages for carboxylic acids than for alcohols, since the decaging for 4-o-OAc takes place more efficiently than for 4-o-OMe, and the decaging of acids is cleaner leading to the formation of fewer side products. Although Wang et al. reported on decaging alcohols from the orthoaniline derivatives, ${ }^{30}$ our finding is that upon decaging of alcohol, more sample degradation takes place. Thus, after the irradiation of 4-o-OAc, alcohol 4-o-OH can be isolated in higher yield (70\%) than after the irradiation of 4-o-OMe (32\%).

The synthetic and biological applicability of the ortho-aniline photocage for carboxylic acid was demonstrated for several examples. The protection of acids can be easily accomplished in high yields under very mild conditions by treatment of an acid with chloride $\boldsymbol{o - 7}$ (Scheme 6 and Table 2). The reaction scope was demonstrated for bulky adamantane-1-carboxylic acid, monobenzylprotected aliphatic adipinic acid, $N$-Boc protected phenylalanine, carboxybenzyl-protected neurotransmitter GABA and nonsteroidal anti-inflammatory drug ibuprofen. All protected esters 11a-e were isolated in high yields. Deprotection of the acids was conducted by irradiation in aqueous $\mathrm{CH}_{3} \mathrm{CN}$ solutions ( $300 \mathrm{~nm}$ ) followed by solution acidification. In such a way, the pure deprotected acids can be easily obtained by extraction from the solution and additional chromatographic purification was not necessary. We showed that with these experimental 
conditions even acid-sensitive Boc group in $\mathbf{1 1 b}$ can remain intact. At the same time, cleaved aniline in the form of alcohol 4-o-OH remains in the aqueous phase, since it is protonated in the acidic solution. Moreover, alcohol 4-o-OH can be extracted after basification of the solution, and in principle, converted to $\boldsymbol{o}-\mathbf{7}$ and re-used in the synthesis. This protective system represents a significant advantage compared to the most commonly used conventional protective groups which are lost in the deprotection; an advantage that is particularly important for large scale synthesis.
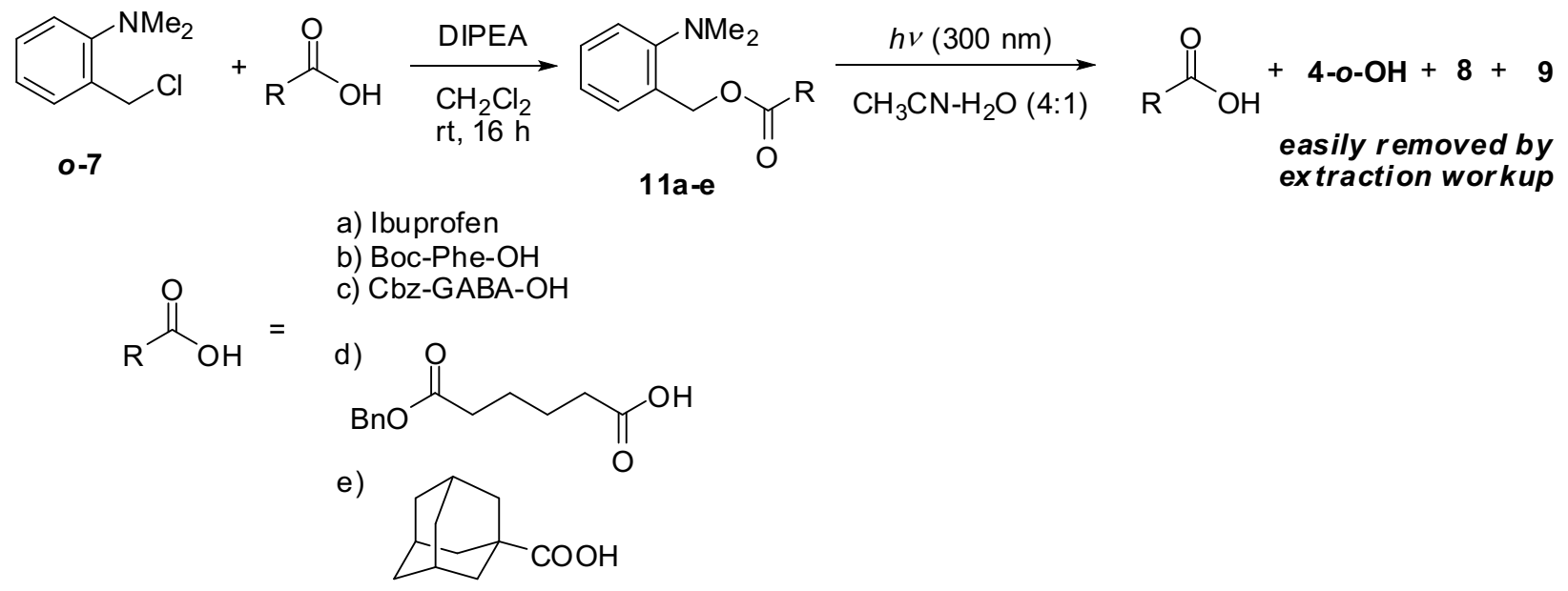

Scheme 6.

Table 2. Yields in the protection with $\boldsymbol{o - 7}$ and photo-deprotection

\begin{tabular}{|l|l|l|l|}
\hline Acid & $\begin{array}{l}\text { Caged } \\
\text { acid }\end{array}$ & $\begin{array}{l}\text { Isolated yield on } \\
\text { caged acid in the } \\
\text { protection reaction } / \%\end{array}$ & $\begin{array}{l}\text { Isolated yield on free } \\
\text { acid in the photo- } \\
\text { deprotection } / \%\end{array}$ \\
\hline
\end{tabular}




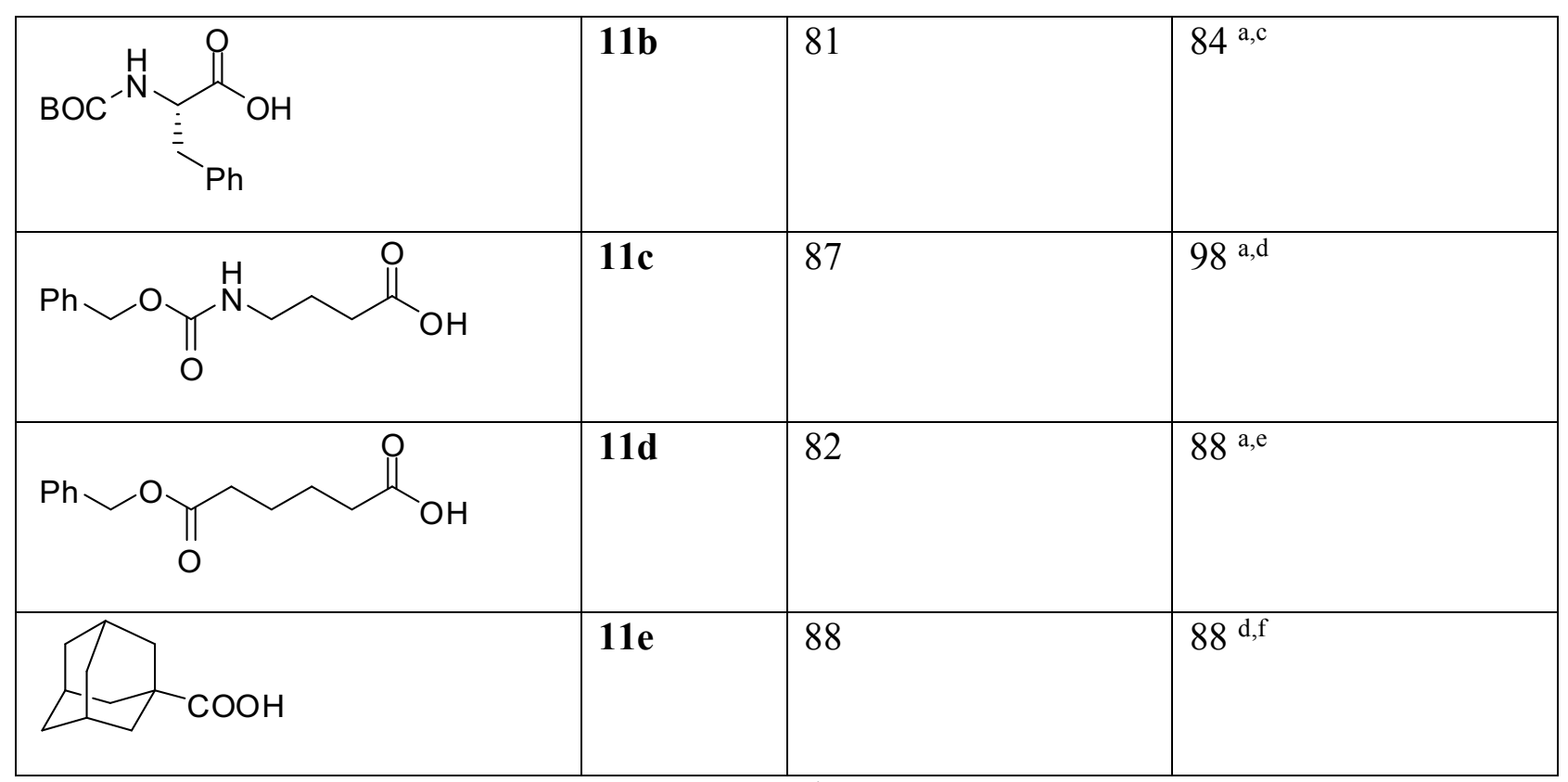

${ }^{a}$ Irradiated with $8 \times 300 \mathrm{~nm}$ lamps $(1 \mathrm{lamp}=8 \mathrm{~W}) ;{ }^{b} 100 \mathrm{mg}$ of 11a in $100 \mathrm{~mL} \mathrm{CH}_{3} \mathrm{CN}_{-} \mathrm{H}_{2} \mathrm{O}(4: 1)$;

${ }^{c} 80 \mathrm{mg}$ of $\mathbf{1 1 b}$ in $100 \mathrm{~mL} \mathrm{CH} \mathrm{CN}_{3} \mathrm{CH}-\mathrm{O}(4: 1) ;{ }^{d} 125 \mathrm{mg}$ of $11 \mathrm{c}$ in $100 \mathrm{~mL} \mathrm{CH}_{3} \mathrm{CN}-\mathrm{H}_{2} \mathrm{O}(4: 1) ;{ }^{e}$ $125 \mathrm{mg}$ of 11d in $100 \mathrm{~mL} \mathrm{CH} \mathrm{CN}_{3}-\mathrm{H}_{2} \mathrm{O}(4: 1) ;{ }^{f} 627 \mathrm{mg}$ of $11 \mathrm{e}$ in $550 \mathrm{~mL} \mathrm{CH}_{3} \mathrm{CN}-\mathrm{H}_{2} \mathrm{O}$ (4:1). Irradiated with $15 \times 300 \mathrm{~nm}$ lamps $(1$ lamp $=8 \mathrm{~W})$.

\section{Photophysical properties of 3-5}

To get a better understanding of anilines 3-5 photochemistry, their photophysical properties were investigated. Absorption spectra are characterized by a low-energy absorption at $\approx 275 \mathrm{~nm}$ for the ortho- and at $\approx 300 \mathrm{~nm}$ for the meta- and para-derivatives (see fig. S1 in the SI). The absorption band corresponds to the $\mathrm{n} \rightarrow \pi^{*}$ transition and population of the $\mathrm{S}_{1}$ state. In $\mathrm{CH}_{3} \mathrm{CN}$ solutions, anilines 3-5 show emission spectra with a maximum at $\approx 350-360 \mathrm{~nm}$. (Table $\mathrm{S} 1$ and Fig S2-S15 in the supporting information). The fluorescence quantum yields ( $\Phi_{\mathrm{f}}$, Table 3 ) were measured in $\mathrm{CH}_{3} \mathrm{CN}$ and $\mathrm{CH}_{3} \mathrm{CN}-\mathrm{H}_{2} \mathrm{O}(1: 4)$ solution by use of quinine sulfate in aqueous $0.05 \mathrm{M}$ 
$\mathrm{H}_{2} \mathrm{SO}_{4}(\Phi=0.55)^{36}$ or naphthalene in cyclohexane $(\Phi=0.19) .{ }^{32}$ The singlet excited state lifetimes were measured by time-correlated single photon counting (SPC, Table 3).

The $\Phi_{\mathrm{f}}$ for methyl ethers in $\mathrm{CH}_{3} \mathrm{CN}$ is about ten times higher than for the corresponding acetyl esters, in line with the higher OAc photochemical reactivity in $\mathrm{S}_{1}$ (see Table 1). The fluorescence for methyl ether derivatives and alcohols in $\mathrm{CH}_{3} \mathrm{CN}$ solutions was best fit to a single exponential function, indicating the presence of only one species in $\mathrm{S}_{1}$. On the contrary, acetyl derivatives exhibit multi-exponential decay of fluorescence. However, the probable reason for the observed multi-exponential fluorescence decay is not the existence of several excited state species, but their photochemical reactivity. Therefore, we do not report these values. Namely, the photochemical decomposition of the OAc samples takes place during the decay collection giving fluorescent alcohols. Nevertheless, the average decay time from $S_{1}$ for the acetyl derivatives is shorter then for the methoxy derivatives (see Fig S16 in the SI), clearly indicating the higher reactivity of acetyls. Furthermore, we have also detected a very short decay of fluorescence for 3-m-OAc in $\mathrm{CH}_{3} \mathrm{CN}$ at $550 \mathrm{~nm}(\approx 50 \mathrm{ps})$ at the wavelength where the emission of the aniline or the corresponding photohydrolysis products $\mathbf{3}-\mathbf{m}-\mathbf{O H}$ is not expected to occur. This fast decay is tentatively assigned to the fluorescence of the photochemically formed carbocation (vide infra).

Table 3. Fluorescence properties of anilines 3-5 in $\mathrm{CH}_{3} \mathrm{CN}$ and $\mathrm{CH}_{3} \mathrm{CN}-\mathrm{H}_{2} \mathrm{O}(1: 4)$ at $\mathrm{pH} 7$.

\begin{tabular}{|l|l|l|l|l|}
\hline Comp. & $\Phi_{\mathrm{f}}\left(\mathrm{CH}_{3} \mathrm{CN}\right)^{\mathrm{a}}$ & $\Phi_{\mathrm{f}}\left(\mathrm{CH}_{3} \mathrm{CN}-\mathrm{H}_{2} \mathrm{O}\right)^{\mathrm{a}}$ & $\tau\left(\mathrm{CH}_{3} \mathrm{CN}\right) / \mathrm{ns}^{\mathrm{b}}$ & $\tau\left(\mathrm{CH}_{3} \mathrm{CN}-\mathrm{H}_{2} \mathrm{O}\right) / \mathrm{ns}$ \\
\hline 4-o-OMe & $0.068 \pm 0.001$ & $0.0055 \pm 0.0002$ & $2.15 \pm 0.01$ & - \\
\hline 4-o-OAc & $0.0050 \pm 0.0003$ & $0.0028 \pm 0.0002$ & & \\
\hline 4-o-OH & $0.06 \pm 0.01$ & - & $1.90 \pm 0.01$ & - \\
\hline 3-m-OMe & $0.110 \pm 0.004$ & $0.029 \pm 0.002$ & $3.16 \pm 0.01$ & \\
\hline
\end{tabular}




\begin{tabular}{|l|l|l|l|l|}
\hline 3-m-OAc & $0.0012 \pm 0.0004$ & $0.005 \pm 0.001$ & & \\
\hline 5-p-OMe & $0.10 \pm 0.02$ & $0.07 \pm 0.02$ & $3.18 \pm 0.01$ & $2.80 \pm 0.01$ \\
\hline 5-p-OAc & $0.07 \pm 0.02$ & $0.05 \pm 0.01$ & $3.03 \pm 0.01$ & \\
\hline 5-p-OH & $0.09 \pm 0.02$ & $0.07 \pm 0.02$ & $3.08 \pm 0.01$ & $2.60 \pm 0.01$ \\
\hline
\end{tabular}

${ }^{a}$ Quantum yields of fluorescence $\left(\Phi_{\mathrm{f}}\right)$ were measured by use of quinine sulfate in $0.05 \mathrm{M}$ aqueous $\mathrm{H}_{2} \mathrm{SO}_{4}\left(\Phi_{\mathrm{f}}=0.55\right)^{36}$ as a reference, or naphthalene in cyclohexane $\left.\left(\Phi_{\mathrm{f}}=0.19\right)\right)^{32} \mathrm{An}$ average value is reported from single experiment by excitation at three different wavelengths. The errors quoted correspond to maximum absolute deviations (see experimental and the SI). ${ }^{b}$ Singlet excited state lifetimes were obtained by global fitting of fluorescence decays measured at several wavelengths by time-correlated single photon counting (see experimental).

Addition of protic solvent $\left(\mathrm{H}_{2} \mathrm{O}\right)$ significantly quenched the fluorescence. The fluorescence quantum yields in aqueous solution at $\mathrm{pH} 7$ are about ten times lower than in $\mathrm{CH}_{3} \mathrm{CN}$, clearly indicating higher photochemical reactivity of 3-5 in aqueous solution, in line with the measured quantum efficiency for the photosolvolysis (Table 1).Furthermore, the fluorescence decays for all molecules (except non-reactive 5-p-OH and 5-p-OMe) in aqueous solution are multiexponential, probably due to sample decomposition and formation of fluorescent products, as seen with $\mathrm{OAc}$ samples in $\mathrm{CH}_{3} \mathrm{CN}$.

In summary, all anilines are photochemically reactive in aqueous solution, as indicated by significant fluorescence quenching by addition of protic solvent. Furthermore, the methyl ethers probably do not undergo photochemical reactions in $\mathrm{CH}_{3} \mathrm{CN}$, due to poor leaving group ability of the methoxide group. On the contrary, acetyl is a much better leaving group, and the heterolysis of esters probably takes place in both $\mathrm{CH}_{3} \mathrm{CN}$ and $\mathrm{CH}_{3} \mathrm{CN}-\mathrm{H}_{2} \mathrm{O}$. 


\section{Laser Flash Photolysis (LFP)}

LFP experiments were conducted to probe for the anticipated carbocation intermediates in the photochemical reactions of $\mathbf{3 - 5}$, and to study their reactivity. The samples were excited with a YAG laser at $266 \mathrm{~nm}$, and the measurements were conducted in $\mathrm{CH}_{3} \mathrm{CN}$ and $\mathrm{CH}_{3} \mathrm{CN}-\mathrm{H}_{2} \mathrm{O}(1: 4)$, since quantum yield measurements and fluorescence spectroscopy indicated different reactivity of the molecules in aqueous and non-aqueous solutions. Prior to the measurements, the solutions were purged by $\mathrm{N}_{2}$ or $\mathrm{O}_{2}$, where the $\mathrm{O}_{2}$ was expected to quench triplet excited states and radical intermediates, but not carbocations.

Results obtained for the least reactive para-derivatives will be described first. These studies enabled us to establish a baseline for the assignation of transients from photochemically reactive, more interesting meta- and ortho-molecules. In $\mathrm{N}_{2}$-purged $\mathrm{CH}_{3} \mathrm{CN}$ solution of 5-p-OMe three transients were detected (Fig S20 in the supporting information). One short-lived transient with $\tau$ $=4 \pm 1 \mu \mathrm{s}$, absorbs over the whole spectrum, whereas the longer-lived transient with $\tau \approx 10 \mu \mathrm{s}$ has a maximum of absorption at $\approx 480 \mathrm{~nm}$. The third transient was detected with $\tau \approx 30 \mu$ s absorbing mainly at $<350 \mathrm{~nm}$ with a maximum at $330 \mathrm{~nm}$. In $\mathrm{O}_{2}$-purged solution, the short-lived transient absorbing over the whole spectrum and the long-lived transient absorbing at $<350 \mathrm{~nm}$ were not detected. Consequently, the transient with the lifetime of $4 \mu \mathrm{s}$ in $\mathrm{N}_{2}$-purged solution was assigned to the triplet state of 5-p-OMe, whereas the transient with a maximum at $330 \mathrm{~nm}$ and lifetime of $\approx 30 \mu$ s most probably corresponds to the benzyl radical 5-p-R. These assignments are based on quenching by $\mathrm{O}_{2}$ and the position of the absorption maxima in the literature precedent. ${ }^{37}$ In $\mathrm{O}_{2}$-purged $\mathrm{CH}_{3} \mathrm{CN}$ solution of 5-p-OMe only one transient was detected absorbing with a maximum at $480 \mathrm{~nm}$ that decayed to the baseline with unimolecular kinetics 
and the lifetime of $10 \pm 1 \mu$ s. Since the same transient with the same lifetime was detected in $\mathrm{N}_{2}$ and $\mathrm{O}_{2}$-purged solution it most probably corresponds to radical-cation 5-p-RC.

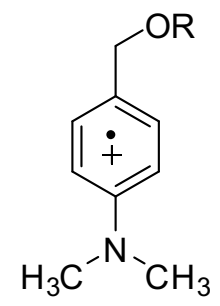

5-p-RC<smiles>[CH2-]c1ccc(N(C)C)cc1</smiles>

$5-p-R$<smiles>[C+]c1ccc(N(C)C)cc1</smiles>

$5-p-C$
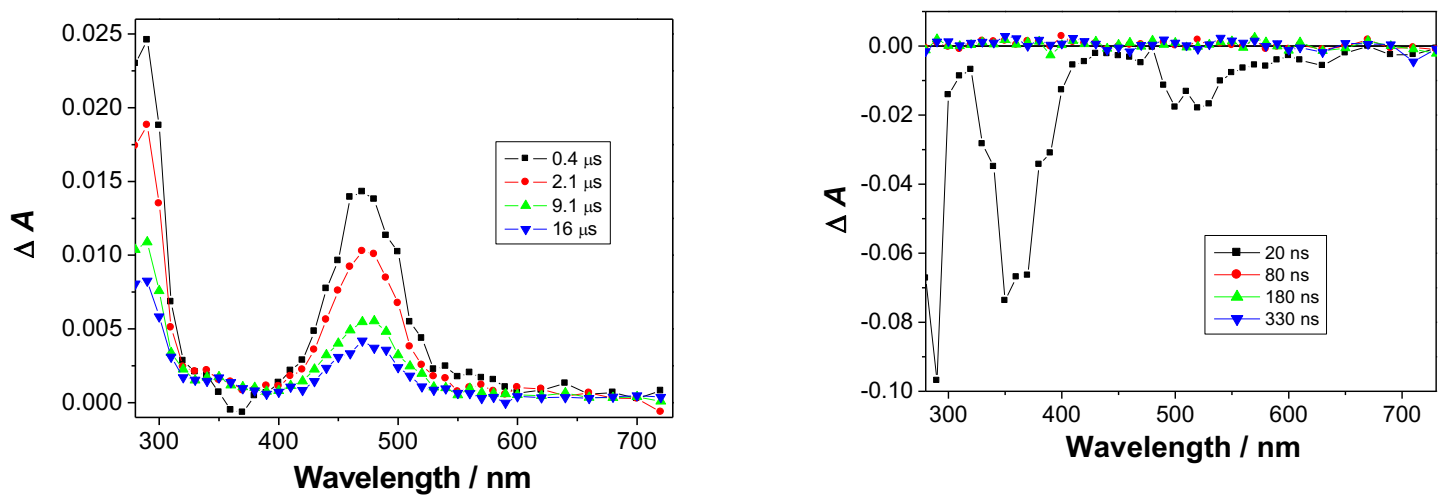

Fig 1. Transient absorption spectra of 5-p-OMe (left) and 3-m-OAc (right) in $\mathrm{O}_{2}$-purged $\mathrm{CH}_{3} \mathrm{CN}$.

In $\mathrm{N}_{2}$-purged aqueous solution of 5-p-OMe, several species were detected (Fig S21 in the supporting information). At short delays after the laser pulse at $\lambda<450 \mathrm{~nm}$, a negative signal was observed due to fluorescence from the sample and bleaching induced by the laser pulse absorption. One short-lived transient with the lifetime of $130 \pm 20 \mathrm{~ns}$ absorbing at 500-600 nm was detected, probably corresponding to the triplet excited state. The triplet undergoes photoionization, as judged by the indication of solvated electron with the very fast decay at $\lambda>$ 
$650 \mathrm{~nm}$. The second transient had an absorption maximum at $480 \mathrm{~nm}$, and resembled the one seen in $\mathrm{CH}_{3} \mathrm{CN}$, but decayed over much longer time with the lifetime of $\approx 0.4 \mathrm{~ms}$. In $\mathrm{O}_{2}$-purged aqueous solution, the long-lived transient with the maximum of absorption at $480 \mathrm{~nm}$ was not quenched $(0.40 \pm 0.05 \mathrm{~ms})$, whereas the short-lived transient absorbing at 500-600 nm was. Thus, in $\mathrm{O}_{2}$-purged $\mathrm{CH}_{3} \mathrm{CN}-\mathrm{H}_{2} \mathrm{O}$ solution, the transient decayed with a lifetime of 50-70 ns (corresponding to $k_{\mathrm{q}}$ of $\approx 1 \times 10^{10} \mathrm{M}^{-1} \mathrm{~s}^{-1}$ ). The transient that was quenched with $\mathrm{O}_{2}$ was assigned to the triplet excited state, whereas the long-lived transient may tentatively be assigned to cation 5p-C or radical-cation 5-p-RC. To assign the transient at $480 \mathrm{~nm}$, quenching with $\mathrm{NaN}_{3}$ was performed (Fig S22 in the SI). The quenching rate constant, $k_{\mathrm{q}}=1 \times 10^{7} \mathrm{M}^{-1} \mathrm{~s}^{-1}$ is significantly lower than the reported diffusion controlled rate constant for benzyl cations $\left(10^{9} \mathrm{M}^{-1} \mathrm{~s}^{-1}\right){ }^{38}$ This finding suggests that the detected species is not a cation 5-p-C, but rather a radical-cation 5-pRC. However, there is no literature precedent for the reactivity of benzyl cation bearing amino substituent. Such a cation would be very stabilized by the presence of $p$-amino substituent, and its electronic structure would resemble to those of quinone methides (QM). Rate constants with azide in the range of $10^{6}-10^{7} \mathrm{M}^{-1} \mathrm{~s}^{-1}$ are very similar to the reported for QMs. ${ }^{39,40}$ Consequently, the transient at $480 \mathrm{~nm}$ was not assigned, it remains ambiguous whether it corresponds to cation 5-p-C or radical-cation 5-p-RC. In $\mathrm{N}_{2}$-purged $\mathrm{CH}_{3} \mathrm{CN}$ solution of 5-p-OAc several transients were detected, similar to the chemistry of 5-p-OMe (Fig S23 in the SI). At $\lambda>500 \mathrm{~nm}$, a transient was detected absorbing with a maximum at $\approx 600 \mathrm{~nm}$ formed with the rate constant $k=$ $2.0 \times 10^{6} \mathrm{~s}^{-1}$. The transient decayed to the baseline with unimolecular kinetics and the lifetime of $\tau$ $=11 \pm 1 \mu \mathrm{s}$, the same as for the signal at $\approx 330 \mathrm{~nm}$. Based on the quenching with $\mathrm{O}_{2}$ and comparison with 5-p-OMe and literature precedent, ${ }^{37}$ the transient with the lifetime of $\tau=11 \pm 1$ $\mu$ s was assigned to benzyl radical 5-p-R. In the range $450-500 \mathrm{~nm}$, a more persistent transient 
was detected that decayed by unimolecular kinetics and lifetime of $\tau=18 \pm 1 \mu \mathrm{s}$, whose formation was less efficient in the $\mathrm{O}_{2}$-purged solution, but it had the same decay kinetics. It was assigned to 5-p-RC.

In aqueous solution of 5-p-OAc (see fig S24 in the SI) a short lived triplet excited state was detected absorbing over the whole spectrum that decayed with the lifetime of $120 \pm 10 \mathrm{~ns}$, whereas at $\lambda>650 \mathrm{~nm}$ solvated electron was detected. Both transients were quenched in the presence of $\mathrm{O}_{2}$. Similar to the photochemistry of 5-p-OMe, a long-lived transient with a lifetime of $\approx 0.4 \mathrm{~ms}$ and maximum at $480 \mathrm{~nm}$ was detected that was not quenched by $\mathrm{O}_{2}$. Quenching of the transient formed from 5-p-OAc absorbing at $480 \mathrm{~nm}$ with $\mathrm{NaN}_{3}$ revealed a similar quenching constant as for 5-p-OMe $k_{\mathrm{q}}=3 \times 10^{6} \mathrm{M}^{-1} \mathrm{~s}^{-1}$, suggesting that the transient correspond to cation 5p-C, or radical-cation 5-p-RC (see fig S25 in the SI).

In addition to ether 5-p-OMe and acetyl derivative 5-p-OAc we have studied by LFP the corresponding alcohol 5-p-OH. In aqueous, air saturated solution three transients were detected, triplet with the lifetime of $\approx 100 \mathrm{~ns}$ absorbing at $400-500 \mathrm{~nm}$, solvated electron absorbing at $\lambda>500 \mathrm{~nm}$ with the lifetime of $30 \mathrm{~ns}$, and cation 5-p-C or radical-cation 5-p-RC absorbing with the maximum at $480 \mathrm{~nm}$ with the lifetime of $0.5 \pm 0.1 \mathrm{~ms}$ (see Fig S26 in the SI).

LFP experiments with $m e t a$-anilines 3-m-OMe and 3-m-OAc were significantly different from the para-derivatives. In $\mathrm{N}_{2}$-purged $\mathrm{CH}_{3} \mathrm{CN}$ solution of 3-m-OMe(Fig S27 in the SI), a transient was detected with a maximum at $460 \mathrm{~nm}$ that decayed to the baseline with unimolecular kinetics with the lifetime of $2.7 \pm 0.1 \mu \mathrm{s}$. Since this transient was not detected in $\mathrm{O}_{2}$-purged solution it was assigned to the triplet state of 3-m-OMe. In $\mathrm{O}_{2}$-purged solution only a negative signal was observed associated to the fluorescence and reversible bleaching of the substrate due to the absorption of the laser flash. Similarly, in the aqueous solution of 3-m-OMe (Fig S28 in the SI) 
only a negative signal was observed. Thus, in $\mathrm{O}_{2}$-purged $\mathrm{CH}_{3} \mathrm{CN}$ or $\mathrm{CH}_{3} \mathrm{CN}-\mathrm{H}_{2} \mathrm{O}$ (1:4) solution, aniline 3-m-OMe does not yield any long-lived intermediate with the lifetime of $>50 \mathrm{~ns}$.

Contrary to 3-m-OMe, in both $\mathrm{N}_{2}$ - and $\mathrm{O}_{2}$-purged $\mathrm{CH}_{3} \mathrm{CN}$ solution of 3-m-OAc only negative signals were detected associated to the fluorescence and reversible bleaching of the substrate due to absorption of the laser flash (Fig 1 right, S29 and S30 in the SI). In addition, a negative signal appeared in the spectra at 450-650 nm, which corresponds to an emission since 3-m-OAc does not absorb in this region. The emission is likely due to the emissive decay of an intermediate formed in its $S_{1}$ in the photochemical reaction. The lifetime for this emission in $\mathrm{N}_{2}$-purged solution is $\approx 35 \mathrm{~ns}$, and it was not significantly quenched by oxygen. This transient is tentatively assigned to the $\mathrm{S}_{1}$ of carbocation 3-m-C.

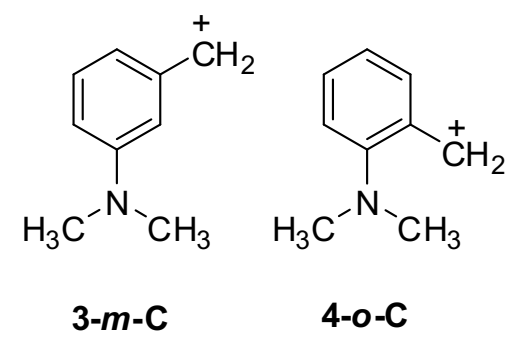

For meta-anilines 3-m-OMe and 3-m-OAc, LFP measurements were conducted in 2,2,2trifluoroethanol (TFE), which is polar, protic, but a non-nucleophilic solvent in which cations and other electrophilic species live longer. ${ }^{41}$ However, for both derivatives, only a negative signal was observed associated to the fluorescence and reversible bleaching of the 3-m-OMe and 3-m-OAc due to absorption of the laser flash (Fig S31 in the SI). This result indicates a high reactivity of carbocation 3-m-C with non-nucleophilic TFE solvents with the rate $>2 \times 10^{7} \mathrm{M}^{-1} \mathrm{~s}^{-1}$ based on the detection limit of the setup used.

LFP experiments with the ortho-derivatives gave the most interesting results. In $\mathrm{N}_{2}$-purged $\mathrm{CH}_{3} \mathrm{CN}$ solution of 4-o-OMe, a transient was detected absorbing over 280-600 nm with the 
lifetime of $11 \pm 2 \mu$ s (Fig S32 in the SI). Since the transient was not detected in the $\mathrm{O}_{2}$-purged solution, it was assigned to the triplet state of 4-o-OMe. In the $\mathrm{O}_{2}$-purged solution only a negative signal was observed associated to the fluorescence and reversible bleaching of the substrate due to absorption of the laser flash. On the contrary, the transient absorption spectra for the solution of 4-o-OMe in $\mathrm{CH}_{3} \mathrm{CN}-\mathrm{H}_{2} \mathrm{O}(1: 4)$ in both $\mathrm{N}_{2}$ - and $\mathrm{O}_{2}$ - purged solution gave rise to a transient with a maximum of absorption at $410 \mathrm{~nm}$ that decayed to the baseline with unimolecular kinetics and a lifetime of $90 \pm 10 \mu$ s (Fig 2 and Fig S33 in the SI). The efficiency of the transient formation or its decay were not affected by $\mathrm{O}_{2}$. This transient was assigned to cation 4-o-C. To prove that the assignment of the transient with $90 \mu$ s to the cation is correct, quenching with sodium azide was conducted (Fig S34 in the SI). The estimated rate constant for $k_{\mathrm{q}}$ of $(1.27 \pm 0.07) \times 10^{9} \mathrm{M}^{-1} \mathrm{~s}^{-1}$ is approaching diffusion limits, in agreement with literature precedent. $^{38}$

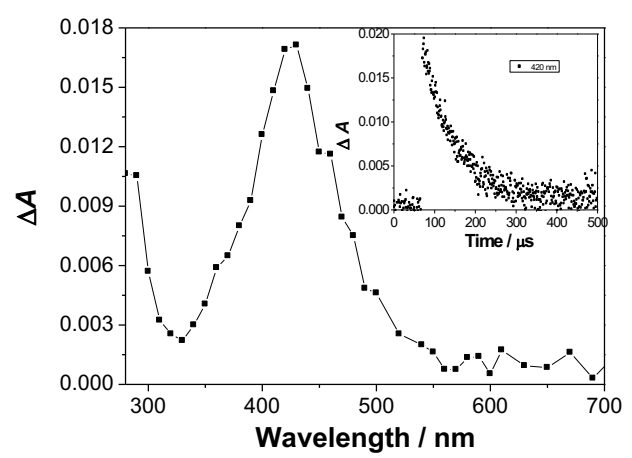

Fig. 2. Transient absorption spectrum of 4-o-OMe in $\mathrm{O}_{2}$-purged $\mathrm{CH}_{3} \mathrm{CN}-\mathrm{H}_{2} \mathrm{O}$ (1:4) solution in the presence of sodium phosphate buffer $(c=0.1 \mathrm{M}, \mathrm{pH}=7)$, detected with the delay of $3 \mu \mathrm{s}$ after the laser pulse. Inset: decay at $420 \mathrm{~nm}$.

Additional verification for the assignment of the transient to 4-o-C was obtained by conducting experiments in solutions of 4-o-OMe at different $\mathrm{pH}$ values. In a basic solution the cation should 
be shorter-lived due to a fast reaction with $\mathrm{OH}^{-}$, whereas at lower $\mathrm{pH}$ values than the $\mathrm{p} K_{\mathrm{a}}$, it is anticipated that the heterolytic cleavage should be less efficient, or should not take place at all. Namely, it is less likely that a positively charged molecule undergoes cleavage and becomes doubly charged. In acidic solution at $\mathrm{pH} 1.43$, a similar transient absorption spectrum was measured as at $\mathrm{pH}$ 7, suggesting the detection of the same intermediate 4-o-C (see Fig S35 and Table S2 in the SI). However, the intensity of the transient absorption for optically matched acidic solutions $\left(A_{266}=0.21\right)$ was significantly lower. This finding is logical since at $\mathrm{pH} 1.43$ the aniline nitrogen should be protonated $\left(\mathrm{p} K_{\mathrm{a}}=4.5-5\right)$. The detection of the transient at such a low $\mathrm{pH}$ indicates that 4-o-OMe probably behaves as a photoacid. That is, photochemical formation of the cation can be facilitated from protonated 4-o-OMe wherein aniline probably first undergoes deprotonation, followed by the cleavage of $\mathrm{CH}_{3} \mathrm{O}^{-}$. With the setup used we could not time-resolve these processes. The short lifetime of the transient in the acidic $\mathrm{HCl}$ solution was explained by the quenching of the transient with $\mathrm{Cl}^{-}$as a nucleophile. An estimate of the quenching rate constant with the value of $k_{\mathrm{q}} \approx 10^{6} \mathrm{M}^{-1} \mathrm{~s}^{-1}$ is in accord with literature precedent. ${ }^{38}$ To check for the influence of $\mathrm{pH}$ on the lifetime of cation 4-o-C, LFP measurements for 4-oOMe were conducted in solutions at different $\mathrm{pH}$ values without $\mathrm{Cl}^{-}$as a nucleophile, in the presence of phosphate buffer. Phosphate anions are weaker nucleophiles than $\mathrm{Cl}^{-}$. The results (Fig S36 and Table S3 in the SI) clearly indicate that cation 4-o-C decays faster in the presence of a base, whereas the efficiency of the transient formation does not change in the $\mathrm{pH}$ range 4.512.3 .

In the LFP experiments for 4-o-OAc, very similar results were obtained as for the ortho-methoxy aniline. However, for the $\mathrm{N}_{2}$-purged $\mathrm{CH}_{3} \mathrm{CN}$ solution of 4-o-OAc, the corresponding triplet excited state was not detected. Instead, a weak transient was observed with a maximum of 
absorption at $\approx 410 \mathrm{~nm}$ (see Fig S37 in the SI). Due to a very weak signal the precise determination of its decay was not warranted. However, the measurement clearly indicated that neither the formation of the transient nor its decay were affected by $\mathrm{O}_{2}$. Based on the comparison with the spectra obtained for 4-o-OMe in $\mathrm{CH}_{3} \mathrm{CN}-\mathrm{H}_{2} \mathrm{O}$, the transient was assigned to cation 4-oC. The transient absorption spectra for the solution of 4-o-OAc in $\mathrm{O}_{2}$-purged $\mathrm{CH}_{3} \mathrm{CN}-\mathrm{H}_{2} \mathrm{O}(1: 4)$ gave the same spectrum as 4-o-OMe with a maximum at $410 \mathrm{~nm}$ that decayed to the baseline with unimolecular kinetics with the lifetime of $80 \pm 5 \mu$ s (Fig S38 in the SI). The transient was assigned to 4-o-C. From the comparison of the transient absorption intensity immediately after the laser pulse (see fig. S39 in the SI) it is evident that the cation is formed more efficiently in aqueous solution than in $\mathrm{CH}_{3} \mathrm{CN}$, probably due to the protonation of the methoxide or acetyl, making them better leaving groups. The assignment of the transient to 4-o-C was further supported by the quenching with $\mathrm{NaN}_{3}$ (see fig. S40 in the SI). The same quenching rate constant was obtained regardless which substrate was photolyzed, acetyl ester, or methyl ether, $k_{\mathrm{q}}=(1.31$ $\pm 0.03) \times 10^{9} \mathrm{M}^{-1} \mathrm{~s}^{-1}$.

LFP experiments with alcohol 4-o-OH in aqueous air-saturated solution also gave rise to the characteristic signal of the cation (see Fig S41 in the SI), with the maximum of absorption at 410 $\mathrm{nm}$ and a lifetime of $72 \pm 1 \mu \mathrm{s}$.

\section{Quantum chemical calculations and Jabonski diagrams}

LFP measurements allowed for the detection of triplet excited states from 3-5, and to investigate the probability for their formation, quantum chemical calculations were performed. Vertical excitations to the singlet and triplet excited states were calculated for 4-o-OMe, 3-m-OMe and 5-p-OMe in the gas phase by TD-DFT using two functionals (see Fig S42 and S43 in the SI). 
Both density functionals gave similar results, however the B3LYP excitation energies were in better accordance with the experimentally measured absorption spectra (Fig S44 in the SI). For ortho-, meta- and para- aniline photocages, the triplet $\mathrm{T}_{1}$ states are significantly lower in energy compared to the singlet $\mathrm{S}_{1}$ state, by $1.06,0.69$ and $0.76 \mathrm{eV}$, respectively (Table $\mathrm{S} 4$ in the $\mathrm{SI}$ ). Although these energy levels can be affected by solvents, the triplet states will always be significantly stabilized compared to the singlet, and the direct intersystem crossing (ISC) between $S_{1}$ and $T_{1}$ is improbable. However, for all aniline derivatives, almost isoenergetic to $S_{1}$ there are the $T_{3}$ or $T_{4}$ states the energy differences of less than $0.1 \mathrm{eV}$. Thus, the ISC between the $\mathrm{S}_{1}$ and $\mathrm{T}_{3}$ or $\mathrm{T}_{4}$ states becomes plausible, accounting for the population of triplets that were detected by LFP. However, these triplets are probably not reactive in the photoheterolysis giving carbocation intermediates. The triplets were detected only for the nonreactive systems with the para- substitution, or for the methyl ethers in $\mathrm{CH}_{3} \mathrm{CN}$ where the ISC is not in competition with the heterolysis which probably takes place much faster.

\section{Discussion}

Irradiation experiments, fluorescence and LFP measurements enabled a complete understanding of the differences in photochemical reactivity between ethers and esters of ortho-, meta- and para-aniline photocages, and allowed for the characterization of reactive intermediates in the photochemical reactions. Understanding the photochemical reaction mechanisms is important for the applications of photocages in different systems, particularly in biology. Namely, photocages, their reactive intermediates and photoproducts may interact with different intracellular molecules and therefore, the knowledge on how the photoreactions occur needs to be accounted for when designing biological assays. 
The para-derivatives are the least photochemically reactive as demonstrated by the lowest quantum efficiency for the photohydrolysis reaction, the highest fluorescence quantum yields, and single-exponential decays of fluorescence. In addition to the radiative deactivation from $\mathrm{S}_{1}$, 5-p-OMe and 5-p-OAc undergo intersystem crossing and populate triplet excited states which were detected by LFP. The triplet excited state undergoes homolytic cleavage and gives a radical pair, as demonstrated by the detection of 5-p-R. Furthermore, the triplet excited state undergoes photoionization and to forms radical-cation 5-p-RC. Direct heterolytic cleavage of the $\mathrm{S}_{1}$ state giving carbocation 5-p-C probably does not take place, or takes place very inefficiently (Scheme 7). The LFP results are in accord with theoretical considerations in literature precedent. ${ }^{42}$ Whereas a strong electron donor facilitates cleavage at the para-position in $\mathrm{S}_{0},{ }^{43}$ in $\mathrm{S}_{1}$ such a cleavage does not take place, in accord with the meta-effect in photochemistry $y^{34,35}$ and reaction pathways taking place via conical intersections. ${ }^{42}$ Thus, the plausible pathway for the formation of cation 5-p-C is mesolytic cleavage of the radical-cation 5-p-RC, or electron transfer in the cage of the radical-pair 5-p-R. In any case, the low quantum yields for the photohydrolysis of 5$\boldsymbol{p}$-OMe and 5-p-OAc which probably take place via cation 5-p-C indicate that the cation is formed very inefficiently which precluded its detection by LFP. 


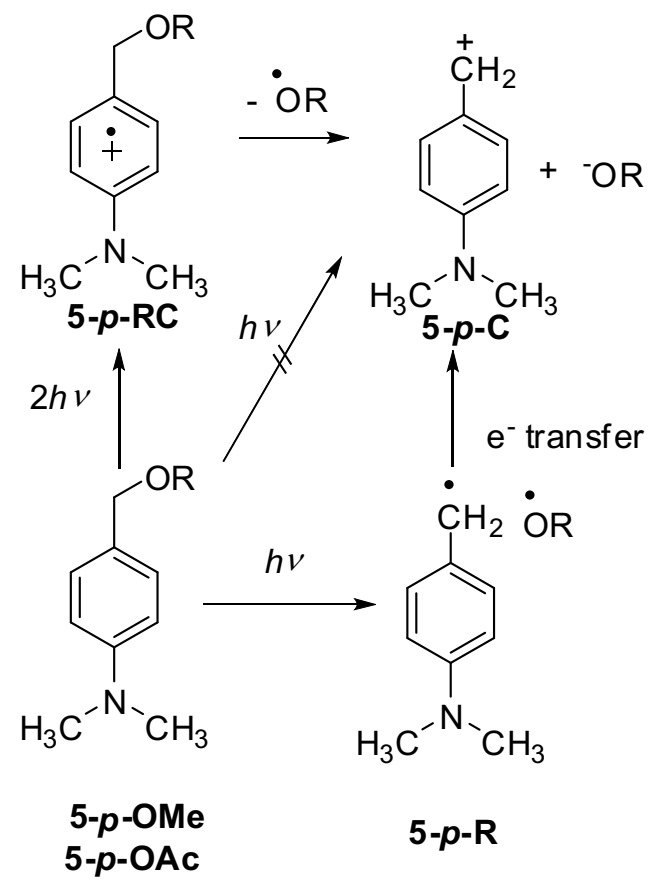

Scheme 7.

meta-Anilines are more photochemically reactive than the para-derivatives. Quantum yields of photohydrolysis, fluorescence and LFP measurements suggest that the heterolytic cleavage of methoxy group in 3-m-OMe in neat $\mathrm{CH}_{3} \mathrm{CN}$ does not take place, or takes place very inefficiently. On the other hand, heterolytic cleavage of 3-m-OAc where the acetyl is a better leaving group is feasible. SPC measurements indicated only one excited state for 3-m-OMe in $\mathrm{CH}_{3} \mathrm{CN}$, whereas mutli-exponential fluorescence decay was detected for 3-m-OAc, suggesting several excited state species. Moreover, LFP measurements suggested that the heterolysis takes place in the singlet excited state giving carbocation $\mathbf{3}-\boldsymbol{m}-\mathbf{C}$ in the excited state that deactivates to $\mathrm{S}_{0}$ by fluorescence (Scheme 8). It is interesting to note that SPC and LFP data for 3-m-OMe do not indicate formation of the excited 3-m-C. These findings are logical, although a detailed computational work on a high level of theory would be required to fully elucidate the processes. The OAc is a better leaving group and the heterolytic cleavage of the OAc most probably takes 
place on the $S_{1}$ surface, reaching 3-m-C in $S_{1}$. On the other hand, the cleavage of OMe probably takes place via a conical intersection giving 3-m-C in the hot ground state. Such a reactivity for $m$-toluidine carbocation has been predicted theoretically. ${ }^{42}$ Since $\mathbf{3}-\boldsymbol{m}$-C is an unstable carbocation in $\mathrm{S}_{0}$, its detection was not warranted (lifetime $<50 \mathrm{~ns}$ ) even in non-nucleophilic solvent such as TFE. Although we were not able to measure the transient spectrum of 3-m-C, its formation was clearly indicated by the isolation of alcohol 3-m-OH and the corresponding $N$ acetyl adduct $\mathbf{1 0}$.

In the photolysis of 3-m-OMe or 3-m-OAc, we did not detect any reduction product, such as toluidine 9 formed in the photolysis of ortho- derivative 4-o-OMe. This finding indicates that the ground state of benzyl cation 3-m-C probably has singlet character. Namely, Falvey et al. demonstrated experimentally ${ }^{44}$ and theoretically ${ }^{45}$ that two amine groups in the meta position stabilize the triplet state of the benzyl cation and make it isoenergetic with the singlet state. Cations in the triplet state do not exhibit typical reactivity with nucleophiles, but react with alkenes, as demonstrated for phenyl cations in the triplet state, ${ }^{46,47}$ and they are anticipated to give reduction products. ${ }^{44}$

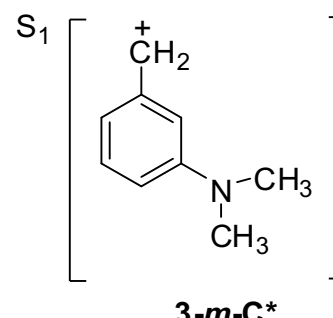

$3-m-C^{*}$

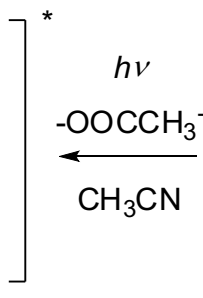

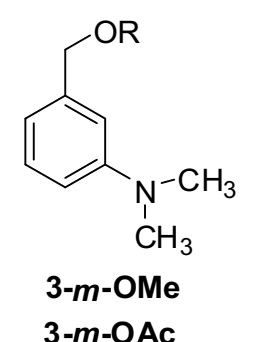

$3-m-\mathrm{OAc}$
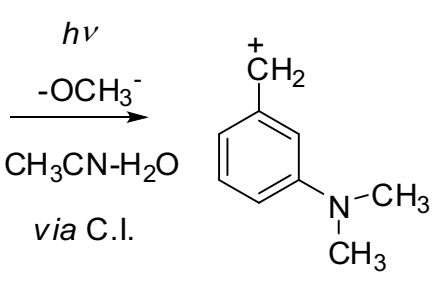

$3-m-\mathrm{C}$

Scheme 8 .

Ortho-anilines undergo efficient photohydrolysis. Similar to meta-derivatives, heterolytic cleavage of the OAc takes place in aqueous and non-aqueous solution, whereas the methoxy group can be cleaved off only in the presence of a protic solvent. These findings were supported 
by quantum yields of fluorescence and SPC data. The single exponential decay was observed only for 4-o-OMe in $\mathrm{CH}_{3} \mathrm{CN}$, whereas for 4-o-OAc and all aqueous solutions muti-exponential decays of fluorescence were detected with a shorter average decay time. For both OMe and OAc, LFP measurements clearly showed the presence of carbocation 4-o-C, which is formed by heterolytic cleavage. The cleavage in $S_{1}$ should be feasible, based on the meta effect, ${ }^{34,35}$ and most probably takes place via a conical intersection between $\mathrm{S}_{1}$ and $\mathrm{S}_{0}{ }^{42}$ Furthermore, cation 4$\boldsymbol{o}$-C is stabilized also in $\mathrm{S}_{0}$ by the electron-donating amine group and the additional resonance structure where the positive charge is at the nitrogen (Scheme 9). This is the first example for the detection of benzyl cation that is stabilized by ortho-amino substituent by laser flash photolysis, but there is a literature precedent for the detection of benzyl cation stabilized by ortho-methoxy group..$^{48}$

The heterolytic cleavage of methoxy group from 4-o-OMe is relatively efficient (Table 1), but it is not clean. In addition to the alcohol 4-o-OH, in the preparative irradiation we isolated product 8 and 9. In particular, methyl derivative $\mathbf{9}$ indicates that the homolytic cleavage takes place as a parallel reaction to the heterolytic cleavage. Competing homolysis and heterolysis reactions were also reported for anilines where the cleavage of carbon-halogen bond took place giving phenyl cations in the triplet excited state. ${ }^{49}$ However, the ground state of cation 4-o-C is probably the singlet state, since 4-o-C exhibits the typical reactivity with nucleophiles and does not bear metaelectron donating substituents that would stabilize the triplet state. ${ }^{42}$ Once radical intermediates are formed in the homolysis, the subsequent reactions give rise to decomposition products. Therefore, ortho-anilines are not so good protective groups for alcohols, as they are for carboxylic acids. 


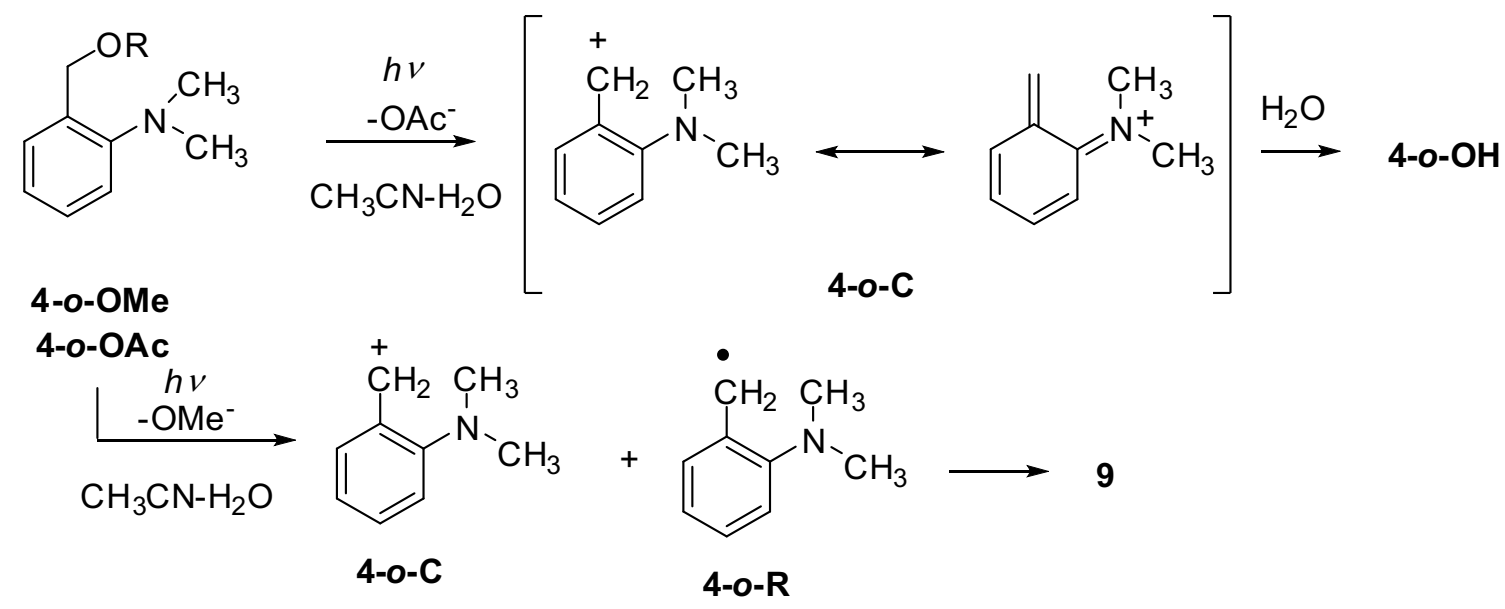

Scheme 9.

Identification of the reaction intermediates and understanding their reactivity is particularly important for applications of photocages in biology. Detection and characterization of carbocations is important since they can alkylate proteins and DNA and lead to cytotoxicity. Furthermore, the mechanistic study unraveled the importance of aqueous media for the decaging, particularly for alcohols. This aspect should be taken into account if photocages are used in the presence of proteins where they may be situated in non-aqueous environment, and therefore, exhibit no reactivity.

\section{Conclusions}

A mechanistic study for a new class of aniline photocages recently introduced by Wang et al. is presented. Compared to the well known and often used ortho-nitrobenzyl photocages, this class of compounds has a significant advantage since the decaging takes place fast and in the photochemical step. Our study unraveled the mechanistic details and enabled the full understanding of the differences for decaging alcohols and carboxylic acids. Whereas para- 
derivatives do not undergo photoheterolysis, meta-and ortho-derivatives undergo efficient photochemical reactions, taking place via carbocation intermediates, yielding alcohols and carboxylic acids in good isolable yields. Furthermore, heterolysis of the meta-acetyl derivatives most probably takes place on the excited state surface affording carbocation in the excited state. On the contrary, heterolysis of the ortho-derivatives probably takes place via a conical intersection and affords carbocations in the ground state that were detected by LFP. Therefore, this result represents an important experimental observation in light of the recent theoretical investigation of the aniline photoheterolysis reactions. ${ }^{42}$ Our main finding, compared to previous reports, is that the meta-derivatives are better photocages for alcohols, whereas ortho-derivatives are better protective groups for carboxylic acids. This selectivity will enable the design of photocages specific for the intended protective group to be used. The applicability of orthohydroxymethyl aniline group as an excellent photocage for carboxylic acids was demonstrated in photorelease of amino acids, nonsteroidal drugs ibuprofen or GABA neurotransmitter, underlying its potential in organic synthesis, biology and medicine.

\section{EXPERIMENTAL SECTION}

General. ${ }^{1} \mathrm{H}$ and ${ }^{13} \mathrm{C}$ NMR spectra were recorded at 300,400 or $600 \mathrm{MHz}(75,100$ and 150 $\mathrm{MHz}$ ) at $25^{\circ} \mathrm{C}$ using TMS as a reference and chemical shifts were reported in ppm. Chemicals were purchased from the usual commercial sources and were used as received. (4aminophenyl)methanol ( $p$-6) was prepared by reduction of 4-nitrobenzaldehyde by use of RaneyNi via known procedure. ${ }^{50}$ Solvents for chromatographic separations were used as delivered from the supplier (p.a. or HPLC grade) or purified by distillation. Dry $\mathrm{CH}_{2} \mathrm{Cl}_{2}$ was obtained after 
standing of distilled $\mathrm{CH}_{2} \mathrm{Cl}_{2}$ over anhydrous $\mathrm{MgSO}_{4}$ overnight, then filtered and stored over $4 \AA$ molecular sieves. Dry methanol was obtained by standard Mg-methoxide method and stored over $3 \AA ̊$ molecular sieves. HRMS analyses were performed on a MALDI-TOF instrument.

[2-(Dimethylamino)phenyl]methanol (4-o-OH). In a flask $(50 \mathrm{~mL}),(2$-aminophenyl)methanol (o-6, $500 \mathrm{mg}, 4.06 \mathrm{mmol})$ and $\mathrm{Na}_{2} \mathrm{HPO}_{4}(2.08 \mathrm{~g}, 14.62 \mathrm{mmol})$ were suspended in dry DMF (15 $\mathrm{mL})$. Methyl iodide $(606 \mu \mathrm{L}, 9.73 \mathrm{mmol})$ was added, and the reaction mixture was stirred at $\mathrm{rt}$ overnight. The next day, reaction mixture was diluted with water $(100 \mathrm{~mL})$ and extracted with diethyl ether $(3 \times 30 \mathrm{~mL})$. The organic layers were combined, washed with brine $(2 \times 15 \mathrm{~mL})$ and $\mathrm{H}_{2} \mathrm{O}(1 \times 20 \mathrm{~mL})$, and dried over anhydrous $\mathrm{Na}_{2} \mathrm{SO}_{4}$. After filtration, the solvent was removed on a rotary evaporator to furnish $549 \mathrm{mg}(89 \%)$ of the product in the form of colorless oil.

[2-(Dimethylamino)phenyl]methanol (4-o-OH): ${ }^{51}{ }^{1} \mathrm{H} \mathrm{NMR}\left(\mathrm{CDCl}_{3}, 600 \mathrm{MHz}\right) \delta / \mathrm{ppm}: 7.28$ $7.23(\mathrm{~m}, 1 \mathrm{H}), 7.20(\mathrm{~d}, 1 \mathrm{H}, J=7.9 \mathrm{~Hz}), 7.16(\mathrm{~d}, 1 \mathrm{H}, J=7.4 \mathrm{~Hz}), 7.07$ (ddd, 1H, $J=8.3 \mathrm{~Hz}, 7.4$ $\mathrm{Hz}, 0.7 \mathrm{~Hz},), 5.42(\mathrm{~s}, 1 \mathrm{H}), 4.81(\mathrm{~s}, 2 \mathrm{H}), 2.72(\mathrm{~s}, 6 \mathrm{H}) ;{ }^{13} \mathrm{C} \mathrm{NMR}\left(\mathrm{CDCl}_{3}, 150 \mathrm{MHz}\right) \delta / \mathrm{ppm}: 152.0$ (s), $135.3(\mathrm{~s}), 128.4(\mathrm{~d}), 128.2(\mathrm{~d}), 124.4(\mathrm{~d}), 120.1(\mathrm{~d}), 64.8(\mathrm{t}), 44.6(\mathrm{q})$.

[3-(Dimethylamino)phenyl]methanol (3-m-OH) and [4-(dimethylamino)phenyl]methanol (5OH). Corresponding (dimethylamino)phenylmethanol (1 g, $8.12 \mathrm{mmol}$ ) and 37\% aq formaline $(6.02 \mathrm{~mL}, 81.2 \mathrm{mmol})$ were dissolved in ethanol $(60 \mathrm{~mL})$ in a round-bottom flask $(250 \mathrm{~mL})$. The reaction mixture was stirred with $\mathrm{PtO}_{2}$ catalyst $(50 \mathrm{mg}$ ) under hydrogen atmosphere (balloon, 1 atm) at $\mathrm{rt}$ overnight. The reaction mixture was then filtered and the solvent was removed on a rotary evaporator to afford the crude product (oil). The product was purified on a column of silica gel using $\mathrm{CH}_{2} \mathrm{Cl}_{2}$ /ethyl acetate (1:1) as eluent to afford the colorless oily product. 
[3-(Dimethylamino)phenyl]methanol (3-m-OH): ${ }^{26} 920 \mathrm{mg}(75 \%) ;{ }^{1} \mathrm{H}$ NMR $\left(\mathrm{CDCl}_{3}, 600\right.$ MHz) $\delta /$ ppm: 7.24 (t, 1H, $J=8.0 \mathrm{~Hz}), 6.76(\mathrm{~s}, 1 \mathrm{H}), 6.72(\mathrm{~d}, 1 \mathrm{H}, J=7.5 \mathrm{~Hz}), 6.70(\mathrm{dd}, 1 \mathrm{H}, J=$

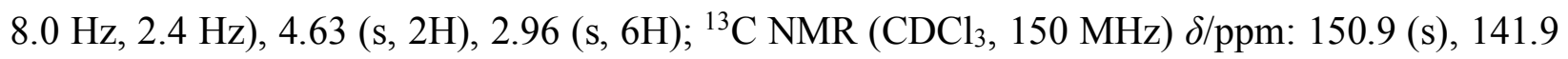
(s), $129.2(d), 115.2(d) 111.9(d), 111.1(d), 65.7(t), 40.6(q)$.

[4-(Dimethylamino)phenyl]methanol (5-p-OH): $5252 \mathrm{mg}(49 \%) ;{ }^{1} \mathrm{H} \mathrm{NMR}\left(\mathrm{CDCl}_{3}, 600 \mathrm{MHz}\right)$ $\delta /$ ppm: 7.23 (d, 2H, $J=8.5 \mathrm{~Hz}), 6.72(\mathrm{~d}, 2 \mathrm{H}, J=8.5 \mathrm{~Hz}), 4.56(\mathrm{~s}, 2 \mathrm{H}), 2.94(\mathrm{~s}, 6 \mathrm{H}) ;{ }^{13} \mathrm{C}$ NMR $\left(\mathrm{CDCl}_{3}, 75 \mathrm{MHz}\right) \delta / \mathrm{ppm}: 150.2,128.8,128.5,112.5,62.2,40.5$.

2-(Chloromethyl)- $N, N$-dimethylaniline (o-7) and 3-(chloromethyl)- $N, N$-dimethylaniline ( $m$ 7). ${ }^{26}$ Corresponding (dimethylamino)phenylmethanol (550 mg, $\left.3.64 \mathrm{mmol}\right)$ was dissolved in dry $\mathrm{CH}_{2} \mathrm{Cl}_{2}(13 \mathrm{~mL})$, cooled to $0{ }^{\circ} \mathrm{C}$, and $\mathrm{SOCl}_{2}$ was added $(480 \mu \mathrm{L}, 6.6 \mathrm{mmol})$. The mixture was stirred at $0{ }^{\circ} \mathrm{C}$ for $20 \mathrm{~min}$, then overnight at $\mathrm{rt}$. The reaction mixture was diluted with $\mathrm{CH}_{2} \mathrm{Cl}_{2}$ and washed with $10 \%$ sodium bicarbonate to neutralize $\mathrm{SOCl}_{2}$ and acid. The organic layer was dried over anhydrous $\mathrm{Na}_{2} \mathrm{SO}_{4}$, filtered and the solvent was removed on a rotary evaporator to afford yellowish oil (90\%) which was used without further purification.

2-(Chloromethyl)- $\mathbf{N}, \boldsymbol{N}$-dimethylaniline (o-7): ${ }^{53} 554 \mathrm{mg}(90 \%) ;{ }^{1} \mathrm{H} \mathrm{NMR}\left(\mathrm{CDCl}_{3}, 600 \mathrm{MHz}\right)$ $\delta /$ ppm: 7.45 (dd, 1H, $J=7.6 \mathrm{~Hz}, 1.6 \mathrm{~Hz}), 7.28(\mathrm{ddd}, 1 \mathrm{H}, J=8.3 \mathrm{~Hz}, 7.1 \mathrm{~Hz}, 1.6 \mathrm{~Hz}), 7.11$ (d, 1H, $J=8.0 \mathrm{~Hz}), 7.08(\mathrm{td}, 1 \mathrm{H}, J=7.6 \mathrm{~Hz}, 0.6 \mathrm{~Hz}), 4.79(\mathrm{~s}, 2 \mathrm{H}), 2.74(\mathrm{~s}, 6 \mathrm{H}) ;{ }^{13} \mathrm{C} \mathrm{NMR}\left(\mathrm{CDCl}_{3}, 150\right.$ MHz) $\delta /$ ppm: 132.1, 131.2, 130.3, 129.3, 123.8, 120.2, 119.8, 45.3, 42.7.

3-(Chloromethyl)- $\boldsymbol{N}, \boldsymbol{N}$-dimethylaniline (m-7): ${ }^{53} 555 \mathrm{mg}(90 \%) ;{ }^{1} \mathrm{H} \mathrm{NMR}\left(\mathrm{CDCl}_{3}, 600 \mathrm{MHz}\right)$ $\delta / \mathrm{ppm}: 7.24$ (t, 1H, $J=7.8 \mathrm{~Hz}), 6.76(\mathrm{~s}, 1 \mathrm{H}), 6.72(\mathrm{~d}, 1 \mathrm{H}, J=7.5 \mathrm{~Hz}), 6.70(\mathrm{dd}, 1 \mathrm{H}, J=8.2,2.4$

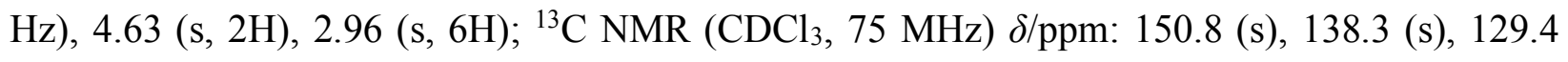
(d), $116.6(d), 112.6(d), 112.4(d), 47.0(t), 40.5(q)$. 
2-(Methoxymethyl)- $N, N$-dimethylaniline $\quad(4-o-O M e)^{53}$ and $\quad 3-($ methoxymethyl)- $N, N-$ dimethylaniline (3-o-OMe). ${ }^{54}$ In a flask $(100 \mathrm{~mL})$, the corresponding (chloromethyl)- $N, N-$ dimethylaniline $(500 \mathrm{mg}, 2.95 \mathrm{mmol})$ was dissolved in dry methanol $(20 \mathrm{~mL})$. The solution of sodium methoxide in methanol was freshly prepared by dissolving $\mathrm{Na}(203 \mathrm{mg}, 8.84 \mathrm{mmol})$ in dry methanol $(20 \mathrm{~mL})$ and added dropwise to the solution of compound in methanol, then stirred at $\mathrm{rt}$ overnight. Methanol was removed on a rotary evaporator and $\mathrm{CH}_{2} \mathrm{Cl}_{2}(50 \mathrm{~mL})$ was added to dissolve the product. The resulting solution was washed with $\mathrm{H}_{2} \mathrm{O}(50 \mathrm{~mL})$, dried over anhydrous $\mathrm{Na}_{2} \mathrm{SO}_{4}$, filtered and solvent was removed on rotary evaporator to furnish light yellow oil. The product was purified on column of silica gel using $\mathrm{CH}_{2} \mathrm{Cl}_{2}$ /ethyl acetate (1:1) as an eluent to afford colorless oily product.

2-(Methoxymethyl)- $\mathbf{N}, \mathbf{N}$-dimethylaniline (4-o-OMe): ${ }^{53} 378 \mathrm{mg}(78 \%) ;{ }^{1} \mathrm{H} \mathrm{NMR}\left(\mathrm{CDCl}_{3}, 300\right.$ MHz) $\delta /$ ppm: $7.43(\mathrm{dd}, 1 \mathrm{H}, J=7.4 \mathrm{~Hz}, 1.1 \mathrm{~Hz}), 7.28-7.21(\mathrm{~m}, 1 \mathrm{H}), 7.10-7.02(\mathrm{~m}, 2 \mathrm{H}), 4.55(\mathrm{~s}$, 2H), 3,43 (s, 3H), $2.71(\mathrm{~s}, 6 \mathrm{H}) ;{ }^{13} \mathrm{C} \mathrm{NMR}\left(\mathrm{CDCl}_{3}, 75 \mathrm{MHz}\right) \delta / \mathrm{ppm}: 152.6$ (s), 132.3 (s), 129.5 (d), $128.3(d), 122.9(d), 118.8(d), 70.7(t), 58.5(q), 45.2(q)$.

3-(Methoxymethyl)- $\boldsymbol{N}, \boldsymbol{N}$-dimethylaniline (3-m-OMe): ${ }^{.4} 358 \mathrm{mg}(73 \%) ;{ }^{1} \mathrm{H} \mathrm{NMR}\left(\mathrm{CDCl}_{3}, 400\right.$ MHz) $\delta /$ ppm: $7.22(\mathrm{t}, 1 \mathrm{H}, J=7.9 \mathrm{~Hz}), 6.74-6.72(\mathrm{~m}, 1 \mathrm{H}), 6.71-6.66(\mathrm{~m}, 2 \mathrm{H}), 4.43(\mathrm{~s}, 2 \mathrm{H}), 3.39$

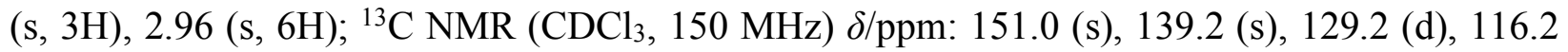
(d), $112.2(\mathrm{~d}), 112.0(\mathrm{~d}), 75.4(\mathrm{t}), 58.2(\mathrm{q}), 40.8(\mathrm{q})$.

4-(Methoxymethyl)- $N, N$-dimethylaniline (5-p-OMe). (4-(Dimethylamino)phenyl)methanol (5p-OH, $155 \mathrm{mg}, 1.03 \mathrm{mmol})$ was dissolved in methanol $(15 \mathrm{~mL})$ and TFA $(0.5 \mathrm{~mL})$ was added. The resulting clear solution was stirred at $\mathrm{rt}$ for $2 \mathrm{~h}$ and then it was transferred to an extraction 
funnel. Diethyl ether $(20 \mathrm{~mL})$ was added and the resulting solution was washed with $0.5 \mathrm{M}$ $\mathrm{NaOH}(50 \mathrm{~mL})$. The organic phase was separated, dried over anhydrous $\mathrm{Na}_{2} \mathrm{SO}_{4}$, filtered and the solvent was evaporated on a rotary evaporator to furnish yellowish oil. The product was purified on column of silica gel using $\mathrm{CH}_{2} \mathrm{Cl}_{2} / \mathrm{EtOAc}$ (95:5) as an eluent to obtain $113 \mathrm{mg}(66 \%)$ of the pure product in the form of colorless oil.

4-(Methoxymethyl)- $N, N$-dimethylaniline (5-p-OMe): ${ }^{53} 113 \mathrm{mg}(66 \%) ;{ }^{1} \mathrm{H}$ NMR $\left(\mathrm{CDCl}_{3}, 300\right.$ MHz) $\delta /$ ppm: 7.21 (d, 2H, $J=8.8 \mathrm{~Hz}), 6.72(\mathrm{~d}, 2 \mathrm{H}, J=8.8 \mathrm{~Hz}), 4.36(\mathrm{~s}, 2 \mathrm{H}), 3.33$ (s, 3H), 2.94

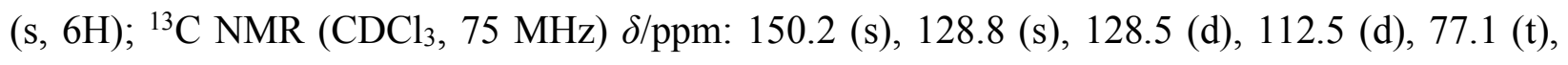
$65.2(\mathrm{q}), 40.5(\mathrm{q}, 2 \mathrm{C})$.

2-(Dimethylamino)benzyl acetate (4-o-OAc) and 3-(dimethylamino)benzyl acetate (3-mOAc). In a flask $(250 \mathrm{~mL})$, the corresponding (dimethylamino)phenylmethanol (400 $\mathrm{mg}, 2.65$ mmol) was dissolved in dry $\mathrm{CH}_{2} \mathrm{Cl}_{2}(30 \mathrm{~mL})$. TEA $(369 \mu \mathrm{L}, 2.65 \mathrm{mmol})$ and $\mathrm{AcCl}(188 \mu \mathrm{L}, 2.65$ mmol) were added. The resulting mixture was stirred at $\mathrm{rt}$ overnight with exclusion of moisture $\left(\mathrm{CaCl}_{2}\right.$ tube on the flask). The next day, the reaction mixture was transferred to an extraction funnel, washed with brine $(50 \mathrm{~mL})$ and $\mathrm{H}_{2} \mathrm{O}(2 \times 25 \mathrm{~mL})$. The organic phase was separated, dried over anhydrous $\mathrm{Na}_{2} \mathrm{SO}_{4}$, filtered and the solvent was evaporated on a rotary evaporator to furnish the crude product in the form of yellow oil. The product was purified on column of silica gel using diethyl ether (for 8) or $\mathrm{CH}_{2} \mathrm{Cl}_{2}$ (for 10) as eluent to afford pale yellow (8) or bright yellow (10) oily product.

2-(Dimethylamino)benzyl acetate (4-o-OAc): ${ }^{51} 470 \mathrm{mg}(92 \%) ;{ }^{1} \mathrm{H} \mathrm{NMR}\left(\mathrm{CDCl}_{3}, 600 \mathrm{MHz}\right)$

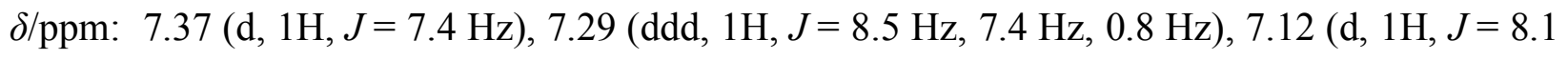
$\mathrm{Hz}), 7.07(\mathrm{t}, 1 \mathrm{H}, J=7.5 \mathrm{~Hz}), 5.25(\mathrm{~s}, 2 \mathrm{H}), 2.70(\mathrm{~s}, 6 \mathrm{H}), 2,12(\mathrm{~s}, 3 \mathrm{H}) ;{ }^{13} \mathrm{C} \mathrm{NMR}\left(\mathrm{CDCl}_{3}, 150\right.$ 
MHz) $\delta /$ ppm: 171.2 (s), 153.2 (s), 130.5 (s), 129.8 (d), 129.1 (d), 123.3 (d), 119.5 (d), 62.8 (t), $45.4(q), 21.2(q)$.

3-(Dimethylamino)benzyl acetate (3-m-OAc): ${ }^{31} 439 \mathrm{mg}(86 \%) ;{ }^{1} \mathrm{H} \mathrm{NMR}\left(\mathrm{CDCl}_{3}, 300 \mathrm{MHz}\right)$ $\delta /$ ppm: 7.26-7.19 (m, 1H), 6.74-6.67 (m, 3H), 5.07 (s, 2H), $2.96(\mathrm{~s}, 6 \mathrm{H}), 2.10(\mathrm{~s}, 3 \mathrm{H}) ;{ }^{13} \mathrm{C}$ NMR $\left(\mathrm{CDCl}_{3}, 75 \mathrm{MHz}\right) \delta / \mathrm{ppm}: 171.1$ (s), 150.9 (s), 136.8 (s), 129.4 (d), 116.6 (d), 112.6 (d), 112.4 (d), $67.1(\mathrm{t}), 40.7$ (q), 21.2 (q).

4-(Dimethylamino)benzyl acetate (5-p-OAc) ${ }^{55}$ [4-(Dimethylamino)phenyl]methanol (5-p-OH, $250 \mathrm{mg}, 1.65 \mathrm{mmol})$ was dissolved in dry $\mathrm{CH}_{2} \mathrm{Cl}_{2}(15 \mathrm{~mL})$. Acetyl chloride $(128 \mu \mathrm{L}, 1.8 \mathrm{mmol})$ and DIPEA $(350 \mu \mathrm{L}, 2 \mathrm{mmol})$ were added at $0{ }^{\circ} \mathrm{C}$. The stirring was continued at $\mathrm{rt}$ overnight (16 h). $\mathrm{CH}_{2} \mathrm{Cl}_{2}(50 \mathrm{~mL})$ was added and the mixture was transferred to an extraction funnel, where it was washed with water $(3 \times 25 \mathrm{~mL})$. The organic phase was separated, dried over anhydrous $\mathrm{Na}_{2} \mathrm{SO}_{4}$ and filtered. After evaporation of the solvent on a rotary evaporator the pure product was obtained (247 mg, 77\%) in the form of colorless oil.

4-(Dimethylamino)benzyl acetate (5-p-OAc): ${ }^{55} 247 \mathrm{mg}(77 \%) ;{ }^{1} \mathrm{H} \mathrm{NMR}\left(\mathrm{CDCl}_{3}, 300 \mathrm{MHz}\right)$ $\delta /$ ppm: 7.28-7.23 (m, 2H), $6.71(\mathrm{~d}, 2 \mathrm{H}, J=8.7 \mathrm{~Hz}), 5.01(\mathrm{~s}, 2 \mathrm{H}), 2.96(\mathrm{~s}, 6 \mathrm{H}), 2.06(\mathrm{~s}, 3 \mathrm{H}) ;{ }^{13} \mathrm{C}$ $\mathrm{NMR}\left(\mathrm{CDCl}_{3}, 75 \mathrm{MHz}\right) \delta / \mathrm{ppm}: 171.2,150.7,130.1,123.4,112.3,66.7,40.5,21.2$.

2-(Dimethylamino)benzaldehyde (8) ${ }^{56}$ The solution of 2-[(dimethylamino)phenyl]methanol (4$\boldsymbol{o}$-OH, $75 \mathrm{mg}, 0.5 \mathrm{mmol})$ in $(5 \mathrm{~mL})$ was cooled to $0{ }^{\circ} \mathrm{C}$ under $\mathrm{N}_{2}$ atmosphere. Dess-Martin periodinane (424 mg, $1 \mathrm{mmol}$ ) was added and stirring was continued at $\mathrm{rt}$ for $1 \mathrm{~h}$, during which color change occurs from light yellow to dark brown. The reaction was quenched by addition of sat. $\mathrm{NaHCO}_{3}$ solution $(10 \mathrm{~mL})$ and then transferred to a separatory funnel. The organic phase 
was collected and the aqueous phase was extracted with $\mathrm{CH}_{2} \mathrm{Cl}_{2}(2 \times 15 \mathrm{~mL})$. The combined extracts were dried over anhydrous $\mathrm{Na}_{2} \mathrm{SO}_{4}$, filtered, and the solvent was removed on a rotary evaporator. The crude product was purified by chromatography on silica gel using $\mathrm{CH}_{2} \mathrm{Cl}_{2}$ as an eluent to afford compound $8(36 \mathrm{mg}, 52 \%)$ in the form of yellow solid.

2-(Dimethylamino)benzaldehyde(8): ${ }^{56} 36 \mathrm{mg}(52 \%) ;{ }^{1} \mathrm{H} \mathrm{NMR}\left(\mathrm{CDCl}_{3}, 300 \mathrm{MHz}\right) \delta / \mathrm{ppm}$ : $10.23(\mathrm{~s}, 1 \mathrm{H}), 7.76(\mathrm{dd}, 1 \mathrm{H}, J=7.7$ and $1.6 \mathrm{~Hz}), 7.50-7.42(\mathrm{~m}, 1 \mathrm{H}), 7.03(\mathrm{~d}, 1 \mathrm{H}, J=8.6 \mathrm{~Hz})$, $6.98(\mathrm{t}, 1 \mathrm{H}, J=7.5 \mathrm{~Hz}), 2.90(\mathrm{~s}, 6 \mathrm{H}) ;{ }^{13} \mathrm{C} \mathrm{NMR}\left(\mathrm{CDCl}_{3}, 75 \mathrm{MHz}\right) \delta / \mathrm{ppm}: 191.2(\mathrm{~d}), 155.8(\mathrm{~s})$, $134.6(d), 130.9(s), 127.0(s), 120.6(s), 117.6(d), 45.5(q)$.

$\boldsymbol{N}, \mathbf{N , 2}$-Trimethylaniline (9). In a flask, $o$-toluidine $(110 \mathrm{mg}, 1 \mathrm{mmol})$ was dissolved in EtOH $(10 \mathrm{~mL}), 37 \%$ aqueous formaline was added $(1 \mathrm{~mL}, 13.4 \mathrm{mmol})$ following by addition of $10 \%$ Pd-C catalyst $(5 \mathrm{mg})$. The observed suspension was stirred under $\mathrm{H}_{2}$ atmosphere (balloon) overnight. The reaction mixture was filtered and the solvent was evaporated on a rotary evaporator. The crude product was purified on column of silica gel using $\mathrm{CH}_{2} \mathrm{Cl}_{2}$ as an eluent to afford compound 9 (98 $\mathrm{mg}, 72 \%)$ in the form of colorless oil.

$\boldsymbol{N}, \boldsymbol{N}, 2-T r i m e t h y l a n i l i n e(9):{ }^{57} 98 \mathrm{mg}(72 \%) ;{ }^{1} \mathrm{H} \mathrm{NMR}\left(\mathrm{CDCl}_{3}, 300 \mathrm{MHz}\right) \delta / \mathrm{ppm}:$ 7.20-7.11 (m, 2H), 7.07-7.00 (m, 1H), $6.94(\mathrm{td}, 1 \mathrm{H}, J=7.3 \mathrm{~Hz}, 1.0 \mathrm{~Hz}), 2.70(\mathrm{~s}, 6 \mathrm{H}), 2.33(\mathrm{~s}, 3 \mathrm{H}) ;{ }^{13} \mathrm{C}$ NMR $\left(\mathrm{CDCl}_{3}, 75 \mathrm{MHz}\right) \delta / \mathrm{ppm}: 152.7$ (s), 132.1 (s), 131.1 (d), 126.4 (d), 122.5 (d), 118.3 (d), 44.2 (q), $18.4(q)$

$N$-[3-(Dimethylamino)benzyl]acetamide (10). In a flask $(50 \mathrm{~mL})$ concentrated ammonia solution $(25 \%, 20 \mathrm{~mL})$ was added to 3 -(chloromethyl)- $N, N$-dimethylaniline $(\boldsymbol{m}-7,112 \mathrm{mg}, 0.67$ mmol) and $50 \% \mathrm{NaOH}$ solution was added $(100 \mu \mathrm{L})$. The resulting solution was stirred at $\mathrm{rt} 1 \mathrm{~h}$, 
then at $50{ }^{\circ} \mathrm{C}$ for $30 \mathrm{~min}$. The reaction was monitored by $\mathrm{TLC}\left(\mathrm{SiO}_{2}, \mathrm{CH}_{2} \mathrm{Cl}_{2}\right.$ as eluent). Chloride has $R_{\mathrm{f}}=0.9$, and the product (amine) remains at the start point. The product was extracted with $\mathrm{CH}_{2} \mathrm{Cl}_{2}(3 \times 30 \mathrm{~mL})$, combined extracts were dried over anhydrous $\mathrm{Na}_{2} \mathrm{SO}_{4}$, filtered and the solvent was removed on a rotary evaporator to obtain yellowish film of amine product, which was immediately used in the next step.

$\mathrm{CH}_{2} \mathrm{Cl}_{2}(15 \mathrm{~mL})$ was added to dissolve the amine, the resulting solution was cooled to $0{ }^{\circ} \mathrm{C}$, then acetyl chloride $(100 \mu \mathrm{L}, 1.4 \mathrm{mmol})$ and DIPEA $(50 \mu \mathrm{L}, 0.29 \mathrm{mmol})$ were added. Stirring was continued at $\mathrm{rt}$ overnight $(16 \mathrm{~h})$. The reaction mixture was concentrated on a rotary evaporator to a volume of approx. $2 \mathrm{~mL}$ and then transferred on a short plug of silicagel and eluted with $\mathrm{CH}_{2} \mathrm{Cl}_{2}$. Pure product $42 \mathrm{mg}$ (33\% for 2 steps) was obtained in the form of pale yellow oil.

$N$-[3-(Dimethylamino)benzyl]acetamide (10): $42 \mathrm{mg}$ (33\% for 2 steps); ${ }^{1} \mathrm{H} \mathrm{NMR} \mathrm{(CDCl} 3,300$ $\mathrm{MHz}) \delta / \mathrm{ppm}:$ 7.27-7.18 (m, 1H), 6.74-6.65 (m, 3H), $5.06(\mathrm{~s}, 2 \mathrm{H}), 2.95(\mathrm{~s}, 6 \mathrm{H}), 2.09(\mathrm{~s}, 3 \mathrm{H}) ;{ }^{13} \mathrm{C}$

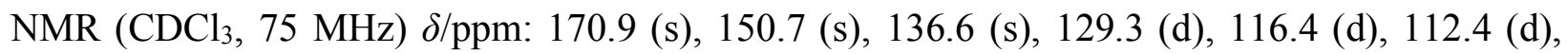
112.3 (d), 66.9 (t), 40.5 (q), 21.0 (q); IR (KBr) $v_{\max } / \mathrm{cm}^{-1}$ 2881, 2807, 2947, 1740, 1606, 1502, 1362, 1227; HRMS (MALDI-TOF) calculated for $\mathrm{C}_{11} \mathrm{H}_{17} \mathrm{~N}_{2} \mathrm{O}^{+} 193.1341$, found 193.1347.

Cbz-GABA-OH ${ }^{58,59} \gamma$-Aminobutyric acid (1.03 g, $\left.10 \mathrm{mmol}\right)$ was dissolved in water $(20 \mathrm{~mL})$ and $\mathrm{NaHCO}_{3}(1.68 \mathrm{~g}, 20 \mathrm{mmol})$ was added. A solution of benzyl chloroformate $(2.3 \mathrm{~mL}, 15$ mmol) in 1,4-dioxane $(10 \mathrm{~mL})$ was added dropwise at $0{ }^{\circ} \mathrm{C}$. The stirring was continued for $16 \mathrm{~h}$ at $\mathrm{rt}$. The product was extracted with diethyl ether $(3 \times 30 \mathrm{~mL})$. The combined organic layers were washed with $1 \mathrm{M} \mathrm{NaOH}(3 \times 20 \mathrm{~mL})$. The organic phase was discarded and the water layer was acidified with $1 \mathrm{M} \mathrm{HCl}(\mathrm{pH}=2)$ and extracted with diethyl ether $(3 \times 30 \mathrm{~mL})$. The organic phase 
was separated, dried over anhydrous $\mathrm{MgSO}_{4}$, filtered and the solvent was evaporated to obtain $1.3 \mathrm{~g}(91 \%)$ of the pure product in the form of colorless oil, which solidifies upon standing.

Cbz-GABA-OH: ${ }^{58} 1.3 \mathrm{~g}(91 \%) ;{ }^{1} \mathrm{H}$ NMR $\left(\mathrm{CDCl}_{3}, 300 \mathrm{MHz}\right) \delta / \mathrm{ppm}: 7.40-7.28$ (m, 5H), 5.09 (s, 2H), 3.36-3.17 (m, 2H), $2.40(\mathrm{t}, 2 \mathrm{H}, J=7.1 \mathrm{~Hz}), 1.84(\mathrm{t}, 2 \mathrm{H}, J=7.1 \mathrm{~Hz}) ;{ }^{13} \mathrm{C} \mathrm{NMR}\left(\mathrm{CDCl}_{3}, 150\right.$ MHz) $\delta /$ ppm: 178.4 (s), 156.6 (s), 136.4 (s), 128.5 (d), 128.09 (d), 128.05 (d), 66.7 (t), 40.2 (t), $31.1(\mathrm{t}), 24.9(\mathrm{t})$.

6-(Benzyloxy)-6-oxohexanoic acid. Adipic acid (2.70 g, $18.5 \mathrm{mmol})$ was dissolved in a mixture of dioxane $(75 \mathrm{~mL})$ and DMF $(75 \mathrm{~mL})$. Benzyl bromide $(2.2 \mathrm{~mL}, 18.5 \mathrm{mmol})$ was added, followed by the addition of $\mathrm{NaHCO}_{3}(1.59 \mathrm{~g}, 19 \mathrm{mmol})$. The resulting suspension was stirred at $90{ }^{\circ} \mathrm{C}$ overnight $(16 \mathrm{~h})$. The solvent was evaporated in vacuum on a rotary evaporator. The solid residue was suspended in ethyl acetate $(100 \mathrm{~mL})$. The organic phase was washed with brine (100 $\mathrm{mL})$ and water $(100 \mathrm{~mL})$. The organic phase was dried over anhydrous $\mathrm{MgSO}_{4}$, filtered and the solvent was evaporated on a rotary evaporator to obtain the pure product $(3.3 \mathrm{~g}, 75 \%)$ in the form of colorless waxy solid.

6-(Benzyloxy)-6-oxohexanoic acid: ${ }^{60} 3.3 \mathrm{~g}(75 \%) ;{ }^{1} \mathrm{H} \mathrm{NMR}\left(\mathrm{CDCl}_{3}, 300 \mathrm{MHz}\right) \delta / \mathrm{ppm}:$ 7.40$7.29(\mathrm{~m}, 5 \mathrm{H}), 5.11(\mathrm{~s}, 2 \mathrm{H}), 2.37(\mathrm{q}, 4 \mathrm{H}, J=6.6 \mathrm{~Hz}), 1.78-1.60(\mathrm{~m}, 4 \mathrm{H}) ;{ }^{13} \mathrm{C} \mathrm{NMR}\left(\mathrm{CDCl}_{3}, 75\right.$ MHz) $\delta /$ ppm: 179.4 (s), 173.1 (s), 135.9 (s), 128.5 (d), 128.2 (d), 128.2 (d), 66.3 (t), 33.8 (t), 24.2 $(\mathrm{t}), 24.0(\mathrm{t})$.

\section{General procedure for the coupling of carboxylic acid with $o-7$}

Chloride o-7 (1.05 eq.) was dissolved in dry $\mathrm{CH}_{2} \mathrm{Cl}_{2}(15 \mathrm{~mL}$ per $1 \mathrm{mmol}$ of chloride) and carboxylic acid derivative ( 1 eq.) was added at $0{ }^{\circ} \mathrm{C}$ followed by the addition of DIPEA (2 eq.). 
The stirring was continued at $\mathrm{rt}$ for $16 \mathrm{~h}$. The reaction was quenched by addition of water (50 $\mathrm{mL}$ ) and the mixture was transferred to a separatory funnel. The organic phase was separated, and the aqueous phase was extracted with $\mathrm{CH}_{2} \mathrm{Cl}_{2}(3 \times 20 \mathrm{~mL})$. The combined extracts were dried over anhydrous $\mathrm{Na}_{2} \mathrm{SO}_{4}$, filtered and the solvent was removed on a rotary evaporator. The crude product was purified on a column of silica gel using $\mathrm{CH}_{2} \mathrm{Cl}_{2}$ or $\mathrm{Et}_{2} \mathrm{O}$ as an eluent.

2-(Dimethylamino)benzyl 2-(4-isobutylphenyl)propanoate (11a). The synthesis was carried out according to the general procedure described above from 2-(chloromethyl)- $N, N$ dimethylaniline (o-7, $187 \mathrm{mg}, 1.1 \mathrm{mmol}$ ), ibuprofen (207 mg, $1 \mathrm{mmol}$ ), and DIPEA (350 $\mu \mathrm{L}, 2$ mmol) in dry $\mathrm{CH}_{2} \mathrm{Cl}_{2}(15 \mathrm{~mL})$. The product was purified on column of silica gel using $\mathrm{CH}_{2} \mathrm{Cl}_{2} /$ hexane $(3: 1 \rightarrow 1: 0)$ as an eluent to afford the pure product $(231 \mathrm{mg}, 68 \%)$ in the form of colorless oil.

2-(Dimethylamino)benzyl 2-(4-isobutylphenyl)propanoate (11a): $231 \mathrm{mg}$ (68\%); ${ }^{1} \mathrm{H}$ NMR $\left(\mathrm{CDCl}_{3}, 300 \mathrm{MHz}\right) \delta / \mathrm{ppm}$ : 7.28-7.13 (m, 4H), 7.11-7.03 (m, 3H), 6.97 (t, 1H, $\left.J=7.4 \mathrm{~Hz}\right), 5.21$ (s, 2H), 3.75 (q, 1H, $J=7.1 \mathrm{~Hz}), 2.61$ (s, 6H), 2.44 (d, 2H, $J=7.1 \mathrm{~Hz}), 1.84(\mathrm{sep}, 1 \mathrm{H}, J=6.7$ $\mathrm{Hz}), 1.52(\mathrm{~d}, 3 \mathrm{H}, J=7.1 \mathrm{~Hz}), 0.89(\mathrm{~d}, 6 \mathrm{H}, J=6.7 \mathrm{~Hz}) ;{ }^{13} \mathrm{C} \mathrm{NMR}\left(\mathrm{CDCl}_{3}, 75 \mathrm{MHz}\right) \delta / \mathrm{ppm}: 174.7$ (s), $152.9(\mathrm{~s}), 140.5$ (s), 137.7 (s), 130.3 (s), 129.4 (s), 129.3 (d, 2C), 128.7 (d), 127.3 (d, 2C), 122.9 (d), 119.1 (d), 62.9 (t), 45.3 (d), 45.1 (d), 45.0 (t, 2C), 30.2 (q), 22.4 (q, 2C), 18.4 (q); IR (KBr) $v_{\max } / \mathrm{cm}^{-1} 3251,3065,2940,1711$; HRMS-MALDI calculated for $\mathrm{C}_{22} \mathrm{H}_{30} \mathrm{NO}_{2}{ }^{+} 340.2277$, found 340.2275 .

2-(Dimethylamino)benzyl ( $N$-tert-butoxycarbonyl)phenylalaninate (11b).The synthesis was carried out according to the general procedure described above from 2-(chloromethyl)- $N, N$ dimethylaniline (o-7, $187 \mathrm{mg}, 1.1 \mathrm{mmol})$, Boc-Phe-OH (266 mg, 1 mmol), and DIPEA (350 $\mu \mathrm{L}$, 
$2 \mathrm{mmol})$ in dry $\mathrm{CH}_{2} \mathrm{Cl}_{2}(15 \mathrm{~mL})$. The product was purified on column of silica gel using $\mathrm{CH}_{2} \mathrm{Cl}_{2}$ as an eluent to afford the pure product (294 mg, 81\%) in the form of colorless oil.

2-(Dimethylamino)benzyl (N-tert-butoxycarbonyl)phenylalaninate (11b): $294 \mathrm{mg}(81 \%) ;{ }^{1} \mathrm{H}$ $\operatorname{NMR}\left(\mathrm{CDCl}_{3}, 300 \mathrm{MHz}\right) \delta / \mathrm{ppm}:$ 7.33-7.20 (m, 5H), 7.16-7.08 (m, 3H), $7.04(\mathrm{t}, 1 \mathrm{H}, J=7.3 \mathrm{~Hz})$, $5.28(\mathrm{~s}, 2 \mathrm{H}), 5.07-4.92(\mathrm{~m}, 1 \mathrm{H}), 4.72-4.57(\mathrm{~m}, 1 \mathrm{H}), 3.19-3.02(\mathrm{~m}, 2 \mathrm{H}), 2.68(\mathrm{~s}, 6 \mathrm{H}), 1.41(\mathrm{~s}, 9 \mathrm{H})$ ${ }^{13} \mathrm{C} \mathrm{NMR}\left(\mathrm{CDCl}_{3}, 75 \mathrm{MHz}\right) \delta / \mathrm{ppm}: 171.9,155.1,153.2,136.0,130.0,129.7,129.4,129.2$, $128.5,126.9,123.2,119.4,79.8,63.6,54.3,45.3,38.3,28.3$; IR $(\mathrm{KBr}) v_{\max } / \mathrm{cm}^{-1} 3405,2880$, 2827, 2786, 1714, 1497, 1372, 1156; HRMS-MALDI calculated for $\mathrm{C}_{23} \mathrm{H}_{30} \mathrm{~N}_{2} \mathrm{O}_{4}\left(-\mathrm{e}^{-}\right) 398.2206$, found 398.2216.

2-(Dimethylamino)benzyl 4-((N-(benzyloxy)carbonyl)amino)butanoate $(11 \mathrm{c})$. The synthesis was carried out according to the general procedure described above from 2-(chloromethyl)- $N, N-$ dimethylaniline (o-7, $175 \mathrm{mg}, 1.03 \mathrm{mmol})$, Cbz-GABA-OH (370 mg, $1.56 \mathrm{mmol})$, DIPEA (350 $\mu \mathrm{L}, 2 \mathrm{mmol})$, and dry $\mathrm{CH}_{2} \mathrm{Cl}_{2}(15 \mathrm{~mL})$. The product was purified on column of silica gel using $\mathrm{CH}_{2} \mathrm{Cl}_{2}$ as an eluent to afford the pure product $(320 \mathrm{mg}, 87 \%)$ in the form of colorless oil.

2-(Dimethylamino)benzyl 4-(( $N$-(benzyloxy)carbonyl)amino)butanoate (11c): $320 \mathrm{mg}(87 \%)$; ${ }^{1} \mathrm{H} \mathrm{NMR}\left(\mathrm{CDCl}_{3}, 300 \mathrm{MHz}\right) \delta / \mathrm{ppm}: 7.42-7.27(\mathrm{~m}, 7 \mathrm{H}), 7.12(\mathrm{dd}, 1 \mathrm{H}, J=8.0 \mathrm{~Hz}, 0.8 \mathrm{~Hz}), 7.05$ (td, 1H, $J=7.5 \mathrm{~Hz}, 1.0 \mathrm{~Hz}), 5.25(\mathrm{~s}, 2 \mathrm{H}), 5.09$ (s, 2H), 4.90 (br. s, 1H), 3.25 (q, 2H, $J=6.4 \mathrm{~Hz})$, $2.69(\mathrm{~s}, 6 \mathrm{H}), 2.42(\mathrm{t}, 2 \mathrm{H}, J=7.2 \mathrm{~Hz}), 1.87$ (quin, $2 \mathrm{H}, J=7.0 \mathrm{~Hz}) ;{ }^{13} \mathrm{C} \mathrm{NMR}\left(\mathrm{CDCl}_{3}, 150 \mathrm{MHz}\right)$ $\delta /$ ppm: 173.2, 156.4, 153.0, 136.6, 130.2, 129.7, 129.0, 128.6, 128.5, 127.0, 123.2, 119.4, 66.7, 62.8, 45.2, 40.5, 31.7, 25.2; IR (KBr) $v_{\max } / \mathrm{cm}^{-1} 3351,3065,3025,2938,2776,1709$; HRMS (MALDI-TOF) calculated for $\mathrm{C}_{21} \mathrm{H}_{28} \mathrm{~N}_{2} \mathrm{O}_{4}{ }^{+} 372.2049$, found 372.2054. 
Benzyl 2-(dimethylamino)benzyl adipate (11d). The synthesis was carried out according to the general procedure described above from 2-(chloromethyl)- $N, N$-dimethylaniline $(\boldsymbol{o}-7,175 \mathrm{mg}$, $1.03 \mathrm{mmol}$ ), 6-(benzyloxy)-6-oxohexanoic acid (236 mg, $1 \mathrm{mmol}$ ), and DIPEA (350 $\mu \mathrm{L}, 2$ mmol) in dry $\mathrm{CH}_{2} \mathrm{Cl}_{2}(10 \mathrm{~mL})$. The product was purified on column of silica gel using $\mathrm{CH}_{2} \mathrm{Cl}_{2}$ as an eluent to afford the pure product (302 $\mathrm{mg}, 82 \%)$ in the form of colorless oil.

Benzyl 2-(dimethylamino)benzyl adipate (11d): $302 \mathrm{mg}(82 \%) ;{ }^{1} \mathrm{H} \mathrm{NMR}\left(\mathrm{CDCl}_{3}, 300 \mathrm{MHz}\right)$ S/ppm: 7.39-7.26 (m, 7H), $7.11(\mathrm{dd}, 1 \mathrm{H}, J=8.0 \mathrm{~Hz}, 0.8 \mathrm{~Hz}), 7.05(\mathrm{dt}, 1 \mathrm{H}, J=7.4 \mathrm{~Hz}, 1.0 \mathrm{~Hz})$, $5.24(\mathrm{~s}, 2 \mathrm{H}), 5.11(\mathrm{~s}, 2 \mathrm{H}), 2.69(\mathrm{~s}, 6 \mathrm{H}), 2.46-2.31(\mathrm{~m}, 4 \mathrm{H}), 1.76-1.64(\mathrm{~m}, 4 \mathrm{H}) ;{ }^{13} \mathrm{C} \mathrm{NMR}\left(\mathrm{CDCl}_{3}\right.$, $75 \mathrm{MHz}$ ) $\delta / \mathrm{ppm}: 173.3$ (s), 173.1 (s), 153.0 (s), 136.0 (s), 130.3 (s), 129.6 (d), 128.9 (d), 128.6 $(\mathrm{d}), 128.2(\mathrm{~d}, 2 \mathrm{C}), 123.1(\mathrm{~d}), 119.3(\mathrm{~d}), 66.2(\mathrm{t}), 62.6(\mathrm{t}), 45.2(\mathrm{q}), 34.0(\mathrm{t}), 33.9(\mathrm{t}), 24.40(\mathrm{t})$, 24.39 (t); IR (KBr) $v_{\max } / \mathrm{cm}^{-1} 2783,1601,1498,1450,939$; HRMS (MALDI-TOF) calculated for $\mathrm{C}_{22} \mathrm{H}_{28} \mathrm{NO}_{4}^{+} 370.2018$, found 370.2024 .

2-(Dimethylamino)benzyl adamantane-1-carboxylate (11e). The synthesis was carried out according to the general procedure described above from 2-(chloromethyl)- $N, N$-dimethylaniline (o-7, $679 \mathrm{mg}, 4 \mathrm{mmol})$, adamantane-1-carboxylic acid (1.18 g, $6.53 \mathrm{mmol})$, and DIPEA (1.9 mL, $11 \mathrm{mmol})$ in dry $\mathrm{CH}_{2} \mathrm{Cl}_{2}(100 \mathrm{~mL})$. The product was purified on column of silica gel using $\mathrm{CH}_{2} \mathrm{Cl}_{2}$ as an eluent to afford the pure product $(1.1 \mathrm{~g}, 88 \%)$ in the form of colorless oil, which solidifies upon standing.

2-(Dimethylamino)benzyl adamantane-1-carboxylate (11e): $1.1 \mathrm{~g}(88 \%) ; \mathrm{mp} 68-70{ }^{\circ} \mathrm{C} ;{ }^{1} \mathrm{H}$ NMR $\left(\mathrm{CDCl}_{3}, 300 \mathrm{MHz}\right) \delta / \mathrm{ppm}: 7.39-7.23(\mathrm{~m}, 2 \mathrm{H}), 7.14-7.01(\mathrm{~m}, 2 \mathrm{H}), 5.22(\mathrm{~s}, 2 \mathrm{H}), 2.70$ (s, 6H), $2.02(\mathrm{~s}, 3 \mathrm{H}), 1.97-1.91(\mathrm{~m}, 6 \mathrm{H}), 1.71(\mathrm{~s}, 6 \mathrm{H}) ;{ }^{13} \mathrm{C} \mathrm{NMR}\left(\mathrm{CDCl}_{3}, 75 \mathrm{MHz}\right) \delta / \mathrm{ppm}: 177.7(\mathrm{~s})$, $152.8(\mathrm{~s}), 130.7$ (s), 129.2 (d), 128.6 (d), 122.9 (d), 119.1 (d), 62.3 (t), 45.1 (q, 2C), 40.8 (s), 38.9 
(t, 3C), 36.5 (t, 3C), 28.0 (d); IR (KBr) $v_{\max } / \mathrm{cm}^{-1}$ 2910, 2849, 1730, 1497, 1454, 1223, 1076, 764;

HRMS (MALDI-TOF) calculated for $\mathrm{C}_{20} \mathrm{H}_{28} \mathrm{NO}_{2}{ }^{+} 314.2120$, found 314.2116.

4-(Ethylthiomethyl)- $\boldsymbol{N}, \boldsymbol{N}$-dimethylaniline (12). Alcohol 5-p-OH (25 mg, $0.17 \mathrm{mmol}$ ) was dissolved in acetonitrile $(3 \mathrm{~mL})$ and ethanethiol $(0.5 \mathrm{~mL}, 6.9 \mathrm{mmol})$ was added, followed by the addition of TFA $(0.5 \mathrm{~mL})$. The resulting solution was stirred at $\mathrm{rt}$ overnight, then solvent and excess of EtSH was removed on a rotary evaporator. The obtained oily residue (TFA salt) was dissolved in $\mathrm{CH}_{2} \mathrm{Cl}_{2}(5 \mathrm{~mL})$ and washed with $1 \mathrm{M} \mathrm{NaOH}(5 \mathrm{~mL})$. The organic phase was collected, dried over anhydrous $\mathrm{Na}_{2} \mathrm{SO}_{4}$ and evaporated. The crude product was purified on a column of silica gel using $\mathrm{CH}_{2} \mathrm{Cl}_{2}$ as an eluent to afford the pure product $(6 \mathrm{mg}, 18 \%)$ in the form of yellow oil.

4-(Ethylthiomethyl)- $\mathbf{N}, \boldsymbol{N}$-dimethylaniline (12): ${ }^{61} 6 \mathrm{mg}(18 \%) ;{ }^{1} \mathrm{H} \mathrm{NMR}\left(\mathrm{CDCl}_{3}, 400 \mathrm{MHz}\right)$

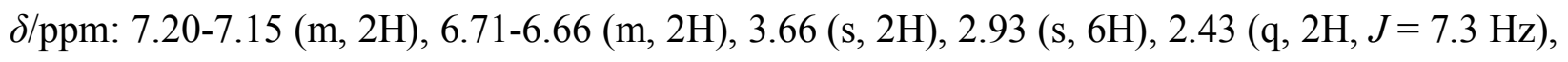
$1.23(\mathrm{t}, 3 \mathrm{H}, J=7.3 \mathrm{~Hz}) ;{ }^{13} \mathrm{C} \mathrm{NMR}\left(\mathrm{CDCl}_{3}, 100 \mathrm{MHz}\right) \delta / \mathrm{ppm}: 149.5$ (s), 129.4 (d), 126.1 (s), $112.5(\mathrm{~d}), 40.6(\mathrm{q}), 35.2(\mathrm{t}), 24.9(\mathrm{t}), 14.3(\mathrm{q})$.

\section{General procedure for photodeprotection of caged acids 11}

Photodeprotections were conducted in a quartz Erlenmeyer flask $(100 \mathrm{~mL})$ or a large quartz tube with a tap-water finger-condenser immersed in the solution. The irradiations were carried out in Luzchem (8 lamps, $300 \mathrm{~nm}$ ) or Rayonet reactor (15 lamps, $300 \mathrm{~nm}$ ). The progress of the reaction was monitored by HPLC.

Compound 11 was dissolved in $\mathrm{CH}_{3} \mathrm{CN}-\mathrm{H}_{2} \mathrm{O}$ (4:1) mixture $(100 \mathrm{~mL})$ and the resulting solution was purged with Ar 30 min prior to the irradiation and during the irradiation. After the 
photodeprotection, the irradiated solution was transferred to a separatory funnel and shaken with $0.5 \mathrm{M} \mathrm{HCl}(50 \mathrm{~mL})$ and diethyl ether $(25 \mathrm{~mL})$. The organic phase was separated and the aqueous phase was extracted with diethyl ether $(2 \times 15 \mathrm{~mL})$. The combined organic extracts were dried over anhydrous $\mathrm{Na}_{2} \mathrm{SO}_{4}$, filtered and the solvent was removed on a rotary evaporator to obtain free carboxylic acid. In all cases, the purification was not necessary, since the deprotected acid was obtained pure. One experiment for compound 11e was carried out on a larger scale (627 mg) whereupon alcohol 4-o-OH (186 mg, 61\%) was regenerated. Identity and purity of the isolated products was checked by ${ }^{1} \mathrm{H}$ NMR. The spectral data for all carboxylic acids is in accordance with previously reported.

Irradiation of 11a. 11a (100 mg, $0.295 \mathrm{mmol})$ was dissolved in $\mathrm{CH}_{3} \mathrm{CN}-\mathrm{H}_{2} \mathrm{O}(4: 1)(100 \mathrm{~mL})$ in a quartz Erlenmeyer flask equipped with a magnetic stirring bar. The resulting solution was purged with Ar 30 min prior to the irradiation and it was irradiated 80 min in the reactor with $8 \times 300 \mathrm{~nm}$ lamps. After extraction workup $45 \mathrm{mg}(84 \%)$ of pure ibuprofen was isolated in the form of white solid.

Irradiation of 11b. 11b (80 mg, $0.201 \mathrm{mmol})$ was dissolved in $\mathrm{CH}_{3} \mathrm{CN}-\mathrm{H}_{2} \mathrm{O}(4: 1)(100 \mathrm{~mL})$ in a quartz Erlenmeyer flask equipped with magnetic stirring bar. The resulting solution was purged with Ar 30 min prior to the irradiation and it was irradiated $80 \mathrm{~min}$ in the reactor with 8 lamps at $300 \mathrm{~nm}$. After the extraction workup the pure Boc-Phe-OH (45 mg, 84\%) was isolated in the form of colorless solid.

Irradiation of 11c. 11c $(125 \mathrm{mg}, 0.337 \mathrm{mmol})$ was dissolved in $\mathrm{CH}_{3} \mathrm{CN}-\mathrm{H}_{2} \mathrm{O}(4: 1)(100 \mathrm{~mL})$ in a quartz Erlenmeyer flask equipped with a magnetic stirring bar. The resulting solution was 
purged with Ar 30 min prior to the irradiation and it was irradiated $80 \mathrm{~min}$ in the reactor with 8 lamps at $300 \mathrm{~nm}$. After the extraction workup the pure Cbz-GABA-OH (70 mg, 98\%) was isolated in the form of colorless oil, which solidified upon standing.

Irradiation of 11d. 11d (125 mg, $0.338 \mathrm{mmol})$ was dissolved in $\mathrm{CH}_{3} \mathrm{CN}-\mathrm{H}_{2} \mathrm{O}(4: 1)(100 \mathrm{~mL})$ in a quartz Erlenmeyer flask equipped with a magnetic stirring bar. The resulting solution was purged with Ar 30 min prior to the irradiation and it was irradiated $80 \mathrm{~min}$ in the reactor with 8 lamps at $300 \mathrm{~nm}$. After the extraction workup the pure Bn-adipic-COOH (70 mg, 88\%) was isolated in the form of colorless waxy solid.

Irradiation of 11e. 11e (627 mg, $2.00 \mathrm{mmol})$ was dissolved in $\mathrm{CH}_{3} \mathrm{CN}-\mathrm{H}_{2} \mathrm{O}(4: 1)(550 \mathrm{~mL})$ in a large quartz tube. The resulting solution was purged with Ar 30 min prior to the irradiation and continuously during the irradiation. The solution was irradiated $65 \mathrm{~min}$ in reactor with 16 lamps at $300 \mathrm{~nm}$. After the extraction workup, the pure Ad-COOH (316 mg, 88\%) was isolated in the form of colorless solid.

Aqueous phase from the extraction was basified with $1 \mathrm{M} \mathrm{NaOH}$ and extracted with diethyl ether $(3 \times 20 \mathrm{~mL})$. The organic extracts were dried over anhydrous $\mathrm{Na}_{2} \mathrm{SO}_{4}$, filtered and the solvent was evaporated on a rotary evaporator to obtain $294 \mathrm{mg}$ of brown oil. The alcohol was purified on column of silica gel using hexane-diethyl ether (1:1) as an eluent to obtain pure aniline alcohol (186 mg, 61\%) in the form of colorless oil.

\section{Irradiation of 5-p-OH in $\mathrm{CH}_{3} \mathrm{CN}$ solution}


5-p-OH (2.5 mg, $0.016 \mathrm{mmol})$ was dissolved in acetonitrile $(2.5 \mathrm{~mL})$ and purged with Ar $20 \mathrm{~min}$ in an UV-vis cuvette. The cuvette was sealed with a cap and irradiated $3 \mathrm{~h}$ in a reactor with 8 lamps at $300 \mathrm{~nm}$. The photoreaction was monitored by HPLC. The presence of photoproduct 11 was confirmed by comparison with the authentic sample of $\mathbf{1 1}$ (commercially available chemical). After $3 \mathrm{~h}$ irradiation, $\mathbf{1 1}$ was formed in 5\% yield.

Irradiation of 5-p-OH in the presence of EtSH. 5-p-OH (2.5 mg, $0.016 \mathrm{mmol})$ was dissolved in acetonitrile $(2.5 \mathrm{~mL})$ and purged with Ar $20 \mathrm{~min}$ in an UV-vis cuvette. EtSH $(100 \mu \mathrm{L}, 1.39$ mmol) was added, the cuvette was sealed with a cap and irradiated 135 min in a reactor with 8 lamps at $300 \mathrm{~nm}$. The photoreaction was monitored by HPLC. The presence of adduct $\mathbf{1 2}$ was confirmed by comparison with authentic sample, which was synthesized for that purpose (described above). After 135 min irradiation 12 was formed in 8\% yield.

\section{Quantum yields of hydrolysis}

Quantum yields for the photohydrolysis reactions were determined by $\mathrm{KI} / \mathrm{KIO}_{3}$, as recently described by us. ${ }^{62}$ The measurement was performed in quartz fluorescence cells that were irradiated from the front side only. Solutions of anilines 3-5 in $\mathrm{CH}_{3} \mathrm{CN}-\mathrm{H}_{2} \mathrm{O}$ (1:4), and actinometers were freshly prepared and their concentrations adjusted to have absorbances of $0.4-$ 0.8 at $254 \mathrm{~nm}$. After adjustment of the concentrations and measurement of the corresponding UV-vis spectra, $2.5 \mathrm{~mL}$ of the solutions were transferred to the cells and the solutions were purged with a stream of $\mathrm{N}_{2}(20 \mathrm{~min})$, and sealed with a cap. The cells were placed in a holder with equal distance from the lamp and were irradiated at the same time in the reactor with 1 lamp at $254 \mathrm{~nm}$ for $30 \mathrm{~s}$. Before and after the irradiation, the samples were taken from the cells by use 
of a syringe and analyzed by HPLC to determine photochemical conversions. The measurement was performed in triplicate and the mean value was reported. All equations for the calculation of quantum yields are given in the supporting info (Eqs. S1-S6).

\section{Steady-State and Time-Resolved Fluorescence Measurements}

Fluorescence measurements were performed on a PTI QM40 fluorometer at $20^{\circ} \mathrm{C}$. All slits (excitation and emission) were set to the bandpass of $2 \mathrm{~nm}$. The spectra were corrected for the fluctuations in lamp intensity and transmission of optics. The samples were excited at 280, 290 or $300 \mathrm{~nm}(280,285$ and 290 for para-derivatives), and the emission was collected in the range $300-590 \mathrm{~nm}$. The excitation spectra were recorded in the range $220-350 \mathrm{~nm}$ by detecting emission at 375 and $400 \mathrm{~nm}$ for the ortho-derivatives, at 350 and 375 for the meta-and paraderivatives. Fluorescence quantum yields were determined by use of quinine sulfate in $0.05 \mathrm{M}$ $\mathrm{H}_{2} \mathrm{SO}_{4}$ as reference $\left(\Phi_{\mathrm{f}}=0.55\right),{ }^{36}$ or naphthalene in cyclohexane $\left(\Phi_{\mathrm{f}}=0.19\right) .{ }^{32}$ Fluorescence decays, collected over 1023 time channels, were obtained on an Edinburgh Instruments OB920 single photon counter using a pulsed laser diode for excitation at $280 \mathrm{~nm}$. The instrument response functions, using LUDOX as the scatterer, were recorded at the same wavelengths as the excitation wavelength and had a half width of IRF was $\approx 0.8 \mathrm{~ns}$. The time increment per channel was $0.049 \mathrm{~ns}$, or $0.020 \mathrm{~ns}$. Emission decays for samples were recorded at $375 \mathrm{~nm}$ and $400 \mathrm{~nm}$ for 4-o-OMe and 4-o-OAc until they reached $3 \times 10^{3}$ counts in the peak channel, or at 350 and 375 and $550 \mathrm{~nm}$ for 3-m-OMe and 3-m-OAc, until the decay reached $1 \times 10^{3}$ counts in the peak channel, and at 350 and $370 \mathrm{~nm}$ until they reached $3 \times 10^{3}$ counts in the peak channel for 5-pOMe and 5-p-OAc. Global analysis of two decays with linked decay times was performed by fitting to sums of exponentials using global Gaussian-weighted non-linear least-squares fitting 
based on Marquardt-Levenberg minimization implemented in the Fast software package from Edinburgh Instruments. Details about fitting procedures and an example of fits can be found in the supporting information (eq. S8and Figs S16-S13).

\section{Laser Flash Photolysis (LFP)}

All LFP studies were performed on a system previously described ${ }^{63}$ using as an excitation source a pulsed Nd:YAG laser at $266 \mathrm{~nm}(<50 \mathrm{~mJ}$ per pulse), with a pulse width of $10 \mathrm{~ns}$. Static cells $(7$ $\mathrm{mm} \times 7 \mathrm{~mm}$ ) were used and the solutions were purged with nitrogen or oxygen for 20 min prior to performing the measurements. Absorbances at $266 \mathrm{~nm}$ were $\sim 0.2-0.5$. For the collection of decays at long time scales, a modification of the setup was used, wherein the probing light beam from the Xe-lamp was not pulsed, as previously described. ${ }^{64}$ Details on the sample preparation for the LFP measurements can be found in the supporting information.

\section{Computational details}

Minimum energy structures of 4-o-OMe, 3-m-OMe and 5-p-OMe have been optimized at the B3LYP/cc-pVDZ level of theory. ${ }^{65,66}$ The vibrational analysis showed that all structures have zero imaginary frequencies. Vertical excitation energies for 20 singlet excited states and 20 triplet states, as well as their oscillator strengths have been calculated using time dependent TDDFT $^{67}$ approach with B3LYP and CAM-B3LYP ${ }^{68}$ density functional and aug-cc-pVTZ basis set. All calculations were performed using Gaussian09 program package. ${ }^{69}$ Molden ${ }^{70}$ was used for a structure manipulation, visualization of geometries and plotting the molecular orbitals. 


\section{Acknowledgement}

These materials are based on work financed by the Croatian Academy of Sciences (HAZU), Croatian Science Foundation (HRZZIP-2014-09-6312), the Natural Sciences and Engineering Research Council of Canada (NSERC- RGPIN-121389-2012), the University of Victoria (UVIC).

Supporting information contains: UV-vis and fluorescence spectra of 3-5, LFP data, computational details and ${ }^{1} \mathrm{H}$ and ${ }^{13} \mathrm{C}$ NMR spectra. This material is available free of charge via the Internet at http://pubs.acs.org.

\section{References:}

${ }^{1}$ Wuts, P. G. M.; Greene, T. W., Greene's Protective Groups in Organic Synthesis, John Wiley \& Sons, Hoboken, 2007.

${ }^{2}$ Bochet, C. G., J. Chem. Soc., Perkin Trans. 1, 2002, 125-142.

${ }^{3}$ Pelliccioli, A. P.; Wirz, J., Photochem. Photobiol. Sci. 2002, 1, 441-458.

${ }^{4}$ Bochet, C. G., Pure Appl. Chem. 2006, 78, 241-247.

${ }^{5}$ Bochet, C. G.; Blanc, A., in Handbook of Synthetic Photochemistry, Albini, A.; Fagnoni, M., Eds., Wiley-VCH, Weinheim, 2010, p. 417-447.

${ }^{6}$ Bochet, C. G., Blanc, A. in CRC Handbook of Organic Photochemistry and Photobiology, Griesbeck, A.G.; Oelgemöller, M.; Ghetti, F., Eds., CRC Press, Boca Raton, 2012, p. 73-93.

${ }^{7}$ Klan, P.; Šolomek, T.; Bochet, C. G.; Blanc, A.; Givens, R.; Rubina, M.; Popik, V.; Kostikov, A.; Wirz, J., Chem.Rev. 2013, 113, 119-191.

${ }^{8}$ Wang, P., Asian J. Org. Chem. 2013, 2, 452-464.

${ }^{9}$ Corrie, J. E. T.; Barth, A.; Munasinghe, V. R. N.; Trentham, D. R.; Hutter, M. C., J. Am. Chem. Soc. 2003, 125, 8546-8554. 
${ }^{10}$ Il'ichev, Y. V.; Schwörer, M. A.; Wirz, J., J. Am. Chem. Soc. 2004, 126, 4581-4596.

${ }^{11}$ Kaplan, J. H.; Forbush, B. III; Hoffman, J. F., Biochemistry 1978, 17, 1929-1935.

${ }^{12}$ Fan, N.-C.; Cheng, F.-Y.; Ho, J.-A. A.; Yeh, C.-S., Angew Chem. Int. Ed. 2012, 51, 88068810 .

${ }^{13}$ Mayer, G.; Heckel, A., Angew Chem. Int. Ed. 2006, 45, 4900-4921.

${ }^{14}$ Nandy, S. K.; Agnes, R. S.; Lawrence, D. S., Org. Lett. 2007, 9, 2249-2252.

${ }^{15}$ Shao, Q.; Xing, B., Chem. Soc. Rev. 2010, 39, 2835-2846.

${ }^{16}$ Givens, R. S.; Jung, A.; Park, C.-H.; Weber, J.; Bartlett, W., J. Am. Chem. Soc. 1997, 119, 8369-8370.

${ }^{17}$ Zhang, K.; Corrie, J. E. T.; Munasinghe, V. N. R.; Wan, P., J. Am. Chem. Soc. 1999, 121, 5625-5632.

${ }^{18}$ Conrad, P. G. II; Givens, R. S.; Hellrung, B.; Rajesh, C. S.; Ramseier, M.; Wirz, J., J. Am. Chem. Soc. 2000, 122, 9346-9347.

${ }^{19}$ Givens, R. S.; Heger, D.; Hellrung, B.; Kamdzhilov, Y.; Mac, M.; Conrad, P. G. II; Cope, E.; Lee, J. I.; Mata-Segreda, J. F.; Schowen, R. L.; Wirz, J., J. Am. Chem. Soc. 2008, 130, 33073309.

${ }^{20}$ Bownik, I.; Šebej, P.; Literák, J.; Heger, D.; Šimek, Z.; Givens, R. S.; Klán, P., J. Org. Chem. 2015, 80, 9713-9721.

${ }^{21}$ Slanina, T.; Šebej, P.; Heckel, A.; Givens, R. S.; Klán, P., Org. Lett. 2015, 17, 4814-4817.

${ }^{22}$ Lukeman, M.; Scaiano, J. C., J. Am. Chem. Soc. 2005, 127, 7698-7699.

${ }^{23}$ Blake, J. A.; Lukeman, M.; Scaiano, J. C., J. Am. Chem. Soc. 2009, 131, 4127-4135.

${ }^{24}$ Wang, P.; Zhou, L.; Zhang, X.; Liang, X., Chem. Commun. 2010, 46, 1514-1516.

${ }^{25}$ Zhou, L.; Yang, H.; Wang, P., J. Org. Chem. 2011, 76, 5873-5881.

${ }^{26}$ Wang, P.; Lu, W.; Devalankar, D. A.; Ding, Z., Org. Lett. 2015, 17, 2114-2117.

${ }^{27}$ Wang, P.; Lu, W.; Devalankar, D.; Ding, Z., Org. Lett. 2015, 17, 170-172.

${ }^{28}$ Wang, P.; Devalankar, D. A.; Lu, W., J. Org. Chem. 2016, 21, 6195-6200. 
${ }^{29}$ Tran, C.; Gallavardin, T.; Petit, M.; Slimi, R.; Dhimane, H.; Blanchard-Desce, M.; Acher, F. C.; Ogden, D.; Dalko, P. I., Org. Lett. 2015, 17, 402-405.

${ }^{30}$ Ding, X.; Wang, P., J. Org. Chem. 2017, 82, 7309-7316.

${ }^{31}$ Hrabák, F.; Hynková, V.; Pivcová, H., Makromol. Chem. 1978, 179, 2593-2601.

${ }^{32}$ Montalti, M.; Credi, A.; Prodi, L.; Gandolfi, M. T. in Handbook of Photochemistry; CRC Taylor and Francis: Boca Raton, 2006.

33 Goldstein, S.; Rabani, J., J. Photochem. Photobiol. 2008, 193, 50-55.

34 Zimmermann, H. E.; Sandel, V. R., J. Am. Chem. Soc. 1963, 85, 915-922.

35 Zimmermann, H. E., J. Am. Chem. Soc. 1995, 117, 8988-8991.

${ }^{36}$ Olmsted, J. III, J. Phys. Chem. 1979, 83, 2581-2584.

37 Tokomura, K.; Ozaki, T.; Nosaka, H.; Saigusa (Ejiri) Y.; Itoh, M., J. Am. Chem. Soc. 1991, 113, 4974-4980.

${ }^{38}$ McClelland, R. A.; Kanagasabapathy, V. M.; Banait, N. S.; Steenken, S., J. Am. Chem. Soc. 1991, 113, 1009-1014

${ }^{39}$ Veljković, J.; Uzelac, L.; Molčanov, K.; Mlinarić-Majerski, K.; Kralj, M.; Wan, P.; Basarić, N., J. Org. Chem. 2012, 77, 4596-4610.

40 Škalamera, Đ.; Bohne, C.; Landgraf, S.; Basarić, N., J. Org. Chem. 2015, 80, 10817-10828.

${ }^{41}$ Cozens, F. L.; Kanagasabapathy, V. M.; McClelland, R. A.; Steenken, S., Can. J. Chem. 1999, 77, 2069-2082.

42 Buck, A. T.; Beck, C. L.; Winter, A. H., J. Am. Chem. Soc. 2014, 136, 8933-8940.

${ }^{43}$ Matikonda, S. S.; Fairhall, J. M.; Tyndall, J. D. A.; Hook, S.; Gamble, A. B., Org. Lett. 2017, $19,528-531$.

${ }^{44}$ Perrotta, R. R.; Winter, A. H.; Falvey, D. E., Org. Lett. 2011, 13, 212-215.

${ }^{45}$ Winter, A. H.; Falwey, D. E.; Cramer, C. J.; Gherman, B. F., J. Am. Chem. Soc. 2007, 129, 10113-10119.

${ }^{46}$ Qrareya, H.; Raviola, C.; Protti, S.; Fagnoni, M.; Albini, A., J. Org. Chem. 2013, 78, 60166024. 
${ }^{47}$ Dichiarante, V.; Fagnoni, M.; Albini, A., J. Org. Chem. 2008, 73, 1282-1289.

${ }^{48}$ Tseng, M.-Y.; Hung, H.-Y.; Sung, K., J. Phys. Chem. A2015, 119, 3905-3912.

${ }^{49}$ Freccero, M.; Fagnoni, M.; Albini, A., J. Am. Chem. Soc. 2003, 125, 13182-13190.

${ }^{50}$ Schwyzer, R.; Sieber, P.; Zatskó. K. Helv. Chim. Acta 1958, 41, 491-498.

${ }^{51}$ Mutschler, E., Arch Pharm Ber Dtsch Pharm Ges 1966, 299, 31-39.

${ }^{52}$ Lai, Y.-Y.; Lin, N.-T.; Liu, Y.-H.; Wang, Y.; Luh T.-J., Tetrahedron 2007, 63, 6051-6055.

${ }^{53}$ Mann, F. G.; Stewart, F. H. C., J. Chem. Soc.1954, 4127-4134.

${ }^{54}$ Minisci, F.; Bernardi, R.; Trabucchi, V.; Grippa, L.; Chimica e l'Industria 1966, 48, 484-486.

${ }^{55}$ Simionescu, C. I.; Percec, V.; Natansohn, A., J. Polym. Sci., Part A: Polym. Chem.1982, 20, 63-71.

${ }^{56}$ Kim, E.; Koh, M.; Lim, B. J.; Park, S. B., J. Am. Chem. Soc. 2011, 133, 6642-6649.

${ }^{57}$ Deping, W.; Daizhi, K.; Fuxing, Z.; Chunlin, Y.; Xiaoming, Z., Adv. Synth. Catal. 2015, 357, 714-718.

${ }^{58}$ Hoggard, L. R.; Zhang, Y.; Zhang, M.; Panic, V.; Wisniewski, J. A., Ji, H.,J. Am. Chem. Soc.2015, 137, 12249-12260.

${ }^{59}$ Cardenal, C.; Vollarth, S. B. L.; Schepers, U.; Bräse, S., Helv. Chim. Acta 2012, 95, 2237-2248.

${ }^{60}$ Wolinsky, J. B.; Ray, W. C.; Colson, Y. L.; Grinstaff, M. W., Macromolecules 2007, 40, 7065-7068.

${ }^{61}$ Degani, J.; Tundo, A., Adv. Mol. Spectrosc., Proocedings of the International Meeting on Molecular Spectroscopy 1962, 2, 562-576.

${ }_{62}$ Škalamera, Đ.; Mlinarić-Majerski, K.; Martin-Kleiner, I.; Kralj, M.; Wan, P.; Basarić, N., J. Org. Chem. 2014, 79, 4390-4397.

${ }^{63}$ Liao, Y.; Bohne, C., J. Phys. Chem. 1996, 100, 734-743.

${ }^{64}$ Mitchell, R. H.; Bohne, C.; Wang, Y.; Bandyopadhyay, S.; Wozniak, C. B., J. Org. Chem. 2006, 71, 327-336.

${ }^{65}$ Becke, A. D., J. Chem. Phys. 1993, 98, 5648-5652.

${ }^{66}$ Lee, C.; Yang, W.; Parr, R. G., Phys. Rev. B 1988, 37, 785-789. 
${ }^{67}$ Runge, E.; Gross, E.K.U., Phys. Rev. Lett. 1984, 52, 997-1000.

${ }^{68}$ Yanai, T.; Tew, D. P.; Handy, N.C., Chem. Phys. Lett. 2004, 393, 51-57.

${ }^{69}$ Frisch, M. J.; Trucks, G. W.; Schlegel, H. B.; Scuseria, G. E.; Robb, M. A.; Cheeseman, J. R.; Scalmani, G.; Barone, V.; Mennucci, B.; Petersson, G. A. et al, Gaussian 09, revision D.01; Gaussian, Inc.: Wallingford, CT, 2009.

${ }^{70}$ Schaftenaar, G.; Noordik, J.H., J. Comp. Aided Mol. Design 2000, 14, 123-134. 